\title{
Endoplasmic Reticulum Stress Sensor IRE1 $\alpha$ Enhances IL-23 Expression by Human Dendritic Cells
}

\begin{abstract}
Saioa Márquez ${ }^{1}$, José Javier Fernández ${ }^{1}$, Eli Terán-Cabanillas ${ }^{2,3,4}$, Carmen Herrero ${ }^{5}$, Sara Alonso ${ }^{5}$, Alicia Azogil' ${ }^{5}$, Olimpio Montero ${ }^{6}$, Takao Iwawaki ${ }^{7}$, Juan R. Cubillos-Ruiz ${ }^{2,3}$, Nieves Fernández ${ }^{1,5+}$ and Mariano Sánchez Crespo ${ }^{5 * t}$

'Departamento de Bioquímica y Biología Molecular, Facultad de Medicina, Universidad de Valladolid, Valladolid, Spain, ${ }^{2}$ Department of Obstetrics and Gynecology, Weill Cornell Medical College, New York, NY, United States, ${ }^{3}$ Sandra and Edward Meyer Cancer Center, Weill Cornell Medical College, New York, NY, United States, ${ }^{4}$ Unidad Académica de Ciencias de la Nutrición y Gastronomía, Universidad Autónoma de Sinaloa, Culiacán, México, ${ }^{5}$ Instituto de Biología y Genética Molecular, CSIC-Universidad de Valladolid, Valladolid, Spain, ${ }^{6}$ Centro para el Desarrollo de la Biotecnología, CSIC, Parque Tecnológico de Boecillo, Valladolid, Spain, Division of Cell Medicine, Medical Research Institute, Kazanawa Medical University, Ishikawa, Japan
\end{abstract}

OPEN ACCESS

Edited by: Takayuki Yoshimoto,

Tokyo Medical University, Japan

Reviewed by:

Cristina Muñoz-Pinedo, Institut d'Investigació Biomédica de Bellvitge, Spain Sinisa Savic,

University of Leeds,

United Kingdom

${ }^{*}$ Correspondence:

Mariano Sánchez Crespo mscres@ibgm.uva.es

tThese authors have contributed equally to this work.

Specialty section: This article was submitted to Inflammation,

a section of the journal

Frontiers in Immunology

Received: 16 March 2017 Accepted: 16 May 2017 Published: 19 June 2017

Citation:

Márquez S, Fernández JJ, Terán-Cabanillas E, Herrero $C$ Alonso S, Azogil A, Montero O,

Iwawaki T, Cubillos-Ruiz JR, Fernández N and Crespo MS (2017)

Endoplasmic Reticulum Stress

Sensor IRE1 $\alpha$ Enhances IL-23 Expression by Human Dendritic Cells.

Front. Immunol. 8:639. doi: 10.3389/fimmu.2017.00639
Human monocyte-derived dendritic cells (DCs) exposed to pathogen-associated molecular patterns (PAMPs) undergo bioenergetic changes that influence the immune response. We found that stimulation with PAMPs enhanced glycolysis in DCs, whereas oxidative phosphorylation remained unaltered. Glucose starvation and the hexokinase inhibitor 2-deoxy-D-glucose (2-DG) modulated cytokine expression in stimulated DCs. Strikingly, IL23A was markedly induced upon 2-DG treatment, but not during glucose deprivation. Since 2-DG can also rapidly inhibit protein N-glycosylation, we postulated that this compound could induce IL-23 in DCs via activation of the endoplasmic reticulum (ER) stress response. Indeed, stimulation of DCs with PAMPs in the presence of 2-DG robustly activated inositol-requiring protein $1 \alpha(\mathbb{R E} 1 \alpha)$ signaling and to a lesser extent the PERK arm of the unfolded protein response. Additional ER stressors such as tunicamycin and thapsigargin also promoted IL-23 expression by PAMP-stimulated DCs. Pharmacological, biochemical, and genetic analyses using conditional knockout mice revealed that IL-23 induction in ER stressed DCs stimulated with PAMPs was IRE $1 \alpha / X$-box binding protein 1-dependent upon zymosan stimulation. Interestingly, we further evidenced PERK-mediated and CAAT/enhancer-binding protein $\beta$-dependent trans-activation of IL23A upon lipopolysaccharide treatment. Our findings uncover that the ER stress response can potently modulate cytokine expression in PAMP-stimulated human DCs.

Keywords: glycolysis, C/EBP $\beta$, 2-deoxy-D-glucose, fungal patterns, IL-23, lactate, unfolded protein response, XBP1

\footnotetext{
Abbreviations: ATF, activating transcription factor; BMDCs, bone marrow-derived dendritic cells; C/EBP $\beta$, CAAT/enhancerbinding protein $\beta$; ChIP, chromatin immunoprecipitation; CHOP, C/EBP homologous protein; COX-2, cyclooxygenase 2; CREB, cAMP response element-binding protein; DCs, dendritic cells; 2-DG, 2-deoxy-D-glucose; ECAR, extracellular acidification rate; eIF $2 \alpha$, elongation initiation factor $2 \alpha$; ER, endoplasmic reticulum; GFPT1, glutamine-fructose-6-phosphate transaminase 1; HIF, hypoxia-inducible factor; IRE1 $\alpha$, inositol-requiring protein $1 \alpha$; IKK, IкB kinase; MS, mass spectrometry; OCR, oxygen consumption rate; PAMPs, pathogen-associated molecular patterns; PERK, protein kinase R-like endoplasmic reticulum kinase; PKM, pyruvate kinase M; UPLC, ultraperformance liquid chromatography; UPR, unfolded protein response; WT, wild type; XBP1, X-box binding protein 1.
} 


\section{INTRODUCTION}

Activation of immune cells induces metabolic changes to control microbial invasion. Glycolysis is needed for many functional tasks in activated macrophages, dendritic cells (DCs), and Th1 and Th17 lymphocytes, e.g., cytokine production and the development of innate immune memory. Consequently, accumulation of lactate and extracellular acidification are prevalent in immune cells stimulated with pathogen-associated molecular patterns (PAMPs). In addition to the production by immune cells, lactate generated by neighbor client cells is a signal of tissue damage that impacts the macrophage response (1). Intracellular lactate stabilizes HIF $1 \alpha$ protein $(2,3)$. An effect shared by other soluble factors found in tumoral and inflammatory milieus. For instance, succinate (4), pyruvate (2), adenosine (5), and hydrogen ions $(6,7)$. Extracellular lactate can activate the membrane receptor GPR81, which transduces extracellular signals through heterotrimeric G proteins in some cell types (8). A property shared by succinate, which enhances the function of some elements of the TLR family by engaging the $G$ protein-coupled receptor GPR91 (9).

This plethora of metabolic changes entails the necessity of control mechanisms to avoid endoplasmic reticulum (ER) stress and cell death. Given that the unfolded protein response (UPR) is the main mechanism evolved to face this risk, it seems likely that elements of the UPR could support the metabolic and transcriptional rewiring elicited by the interaction of phagocytes with PAMPs. Among the components of the UPR, inositolrequiring protein $1 \alpha$ (IRE1 $\alpha)$ is critical to DCs activity since its endoribonuclease domain enables the activation of the X-box binding protein 1 (XBP1) transcription factor (10), which has been demonstrated to control DCs function under diverse physiological and pathological conditions (11). XBP1 also sustains the production of TNF $\alpha$ and IL-6 in macrophages upon TLRdriven activation (12). The clinical relevance of these findings is highlighted by the recent description of the role of XBP1 in the control of antitumor immunity and in the disruption of DCs homeostasis (13), as well as by sound hypotheses associating ER stress caused by HLA-B27 misfolding with IL-23 production in a rat model of spondyloarthritis (14) and the involvement of the IL-23/IL-17 axis in triggering tumor-elicited inflammation and tumor growth (15). These findings have encouraged the search of mechanisms associating the UPR with the transcriptional regulation of IL23A, the gene encoding the p19 chain of IL-23. One report described the involvement of C/EBP homologous protein (CHOP), a transcription factor activated in the UPR, when ER stress occurred in the presence of TLR agonists (16), and another report showed an increase of IL23A transcription upon inhibition of ataxia telangiectasia mutated kinase that correlated with an increase of the mRNA of spliced XBP1 (17). However, other studies have shown inhibition of the activating transcription factor 4 (ATF4)/CHOP branch of the UPR by TLR signaling $(18,19)$ and the actual involvement of ATF2 and NF- $\mathrm{KB}$ in the trans-activation of $I L 23 A$ in the absence of a definite UPR activation $(20,21)$. Given the role of glycolysis during immune cell activation, 2-deoxy-D-glucose (2-DG) has been used as a surrogate of glucose deprivation in experimental studies. 2-DG is phosphorylated by hexokinase and this leads to the competitive inhibition of the enzyme (22). The use of 2-DG has disclosed the central function of glucose metabolism in bacterial and viral infection by showing in the latter model the lethality associated with 2-DG treatment by a mechanism involving type I IFN signaling and Ddit3/CHOP (23). However, 2-DG is not only a glucose mimetic, it is also the product resulting from the loss of the hydroxyl group attached at carbon-2 of mannose. Given that mannose is present in bodily fluids at much lower concentrations than glucose, 2-DG exerts a stronger competition for mannose metabolism than that exerted on glucose (24). This impinges on reactions using mannose as a substrate, including the formation of the dolichol-linked oligosaccharide Glc3-Man9-GlcNAc2 involved in the initial steps of N-linked glycosylation. The functional relevance of this mechanism has been underscored in several models. For instance, 2-DG inhibits cell surface expression of NKG2D ligands (25), and reduces N-glycosylation and activity of COX-2 (26), a key enzyme for prostaglandin metabolism that contains four glycosylated asparagines, three of which are located in the active center and required for proper protein folding and catalysis (27). In this study, we analyzed the bioenergetic rewiring of human DCs stimulated with the fungal glucan zymosan and bacterial lipopolysaccharide (LPS) and investigated how the UPR modulates cytokine expression. Here, we show (i) a rapid enhancement of glycolysis and the maintenance of oxidative phosphorylation in human DCs; (ii) robust activation of the IRE1 $\alpha / \mathrm{XBP} 1 \mathrm{arm}$ of the UPR by $2-\mathrm{DG}$ in the presence of PAMPs, whereas the sole addition of 2-DG induced DDIT3/CHOP expression; and (iii) a robust enhancement of IL23A trans-activation by 2-DG associated with the induction of the UPR that shows some differences as to the arms triggered by the different PAMPs. An IRE1 $\alpha / \mathrm{XBP} 1-$ dependent mechanism is involved in response to zymosan, whereas the response to LPS depends on IRE1 $\alpha$ and PERK, as well as on the recruitment of CAAT/enhancer-binding protein $\beta(\mathrm{C} / \mathrm{EBP} \beta)$. Taken together, these findings demonstrate a strong influence of the UPR on the cytokine-signature elicited by stimulation of DCs.

\section{MATERIALS AND METHODS}

\section{Cells and Reagents}

Dendritic cells were obtained from human mononuclear cells collected from pooled buffy coats of healthy donors provided by Centro de Hemoterapia de Castilla y León. The differentiation of monocytes was carried out in the presence of GM-CSF and IL-4 for 5 days. Culture was carried out in RPMI 1640 medium containing $11.1 \mathrm{mM} \mathrm{D}$-glucose, $4 \mathrm{mM} \mathrm{L}$-glutamine, and $1 \mathrm{mM}$ pyruvate. $10 \%$ FBS was maintained during the differentiation process and reduced to $2 \%$ prior to the initiation of the experiments. Glucose starving experiments were carried out in BioWhittaker ${ }^{\circledR}$ RPMI 1640 medium, containing L-glutamine, without glucose. These conditions were used to replicate the experimental setting used in the Seahorse assays. For the characterization of the cell population as DCs, the expression of CD11c, CD40, and CD86 was assayed. Briefly, cells were centrifuged for $5 \mathrm{~min}$ at $350 \mathrm{~g}$ and resuspended in PBS. Ab was added at the concentration of $0.5 \mu \mathrm{g}$ 
for $5 \times 10^{5}$ cells and incubated for $45 \mathrm{~min}$ at $4^{\circ} \mathrm{C}$. When the $\mathrm{Ab}$ was labeled with fluorochrome, cells were washed and fixed in $1 \%$ formaldehyde. In the case of non-labeled $\mathrm{Ab}$, indirect immunofluorescence was carried out using a labeled secondary Ab before washing and formaldehyde fixation steps. Isotype-matched irrelevant $\mathrm{Ab}$ was used as control. The analysis was performed in a Gallios Flow Cytometer. At least 10,000 cells were analyzed per sample. Kaluza software version 1.1 (Beckman Coulter) was used for quantitative data analysis. Ern $1^{\mathrm{f} / \mathrm{f}} \mathrm{Vav1}$-Cre mice were obtained by Dr. Cubillos-Ruiz through a collaboration with Prof. Takao Iwawaki. Bone marrow from the femora and tibiae was used to obtain bone marrow-derived dendritic cells (BMDCs) from C57BL/6 [wild type (WT)], Ern1 $1^{\mathrm{f} / \mathrm{f}}$, and Ern $1^{\mathrm{f} / \mathrm{f}}$ Vav1-Cre mouse by incubation in media supplemented with $20 \mathrm{ng} / \mathrm{mL}$ recombinant murine GM-CSF. Cells were harvested at day 7 of differentiation and used directly for subsequent studies. The inhibitors of the ribonuclease activity of IRE1 $\alpha$, MK8866, and $4 \mu 8 \mathrm{C}$ were a gift from Dr. John Patterson from MannKind Corporation, Valencia, CA, USA (28) and purchased to Tocris, respectively. The PERK inhibitors GSK2606414 and AMG PERK $44(29,30)$ were from Sellenckchem and Tocris, respectively. Tunicamycin was from Calbiochem. 2-DG, LPS, thapsigargin, and zymosan were from Sigma.

\section{Ethics Statement}

The study was approved by the Bioethical Committee of the Spanish Council of Research (CSIC) and the written informed consent of all healthy donors was obtained at Centro de Hemoterapia y Hemodonación de Castilla y León Biobank. The participants received written consent according to the regulations of the Biobank and the researchers received the samples in an anonymous way. The process is documented by the Biobank authority according to the specific Spanish regulations. The animal experiments were carried out with permission of the local authority and conform to institutional standards. The ethics committee approved this procedure before starting the study.

\section{Bioenergetic Studies}

Bioenergetic analyses of human DCs were carried out using the Seahorse Bioscience XF24 Extracellular Flux analyzer (Seahorse Bioscience). DCs were stimulated and either adhered immediately to polyornithine-coated Seahorse plates or after $4 \mathrm{~h}$ of incubation. To normalize the recording of data, results are referred to $\mu \mathrm{g}$ of protein. Extracellular acidification rate (ECAR) and oxygen consumption rate (OCR) were analyzed according to the XF Cell Mito Stress Test kit protocol in XF media (non-buffered RPMI medium 1640 containing $11.1 \mathrm{mM}$ glucose, $4 \mathrm{mM}$ L-glutamine, and $1 \mathrm{mM}$ sodium pyruvate), under basal conditions, and in response to $1 \mu \mathrm{M}$ oligomycin, $1.5 \mu \mathrm{M}$ FCCP, and $100 \mathrm{nM}$ rotenone plus $1 \mu \mathrm{M}$ antimycin $\mathrm{A}$.

\section{Lactate Assay}

Lactate was assayed using a colorimetric test in cell supernatants centrifuged at $13,000 \mathrm{~g}$ for $10 \mathrm{~min}$ to remove insoluble material and deproteinized by filtration with $3 \mathrm{kDa}$ MWCO spin filters to

remove lactate dehydrogenase. The soluble fraction was directly assayed using a Lactate Assay Kit II from Sigma.

\section{XBP1 Splicing Assay}

This was carried out by RT-PCRs with primers spanning the unspliced regions (Table 1). The PCR conditions were $5 \mathrm{~min}$ at $95^{\circ} \mathrm{C}$ (hot start), 45 cycles of denaturation at $95^{\circ} \mathrm{C}$ for $15 \mathrm{~s}$, annealing at $60^{\circ} \mathrm{C}$ for $20 \mathrm{~s}$ and elongation at $72^{\circ} \mathrm{C}$ for $1 \mathrm{~min}$. Final extension was carried out at $72^{\circ} \mathrm{C}$ for $5 \mathrm{~min}$. Gel electrophoresis was carried out in 3\% agarose and spliced XBP1 and unspliced $X B P 1$ bands visualized by GelRed ${ }^{\mathrm{TM}}$ staining.

\section{Pyruvate Kinase M (PKM) mRNA Expression}

Pyruvate kinase $\mathrm{M}$ isoforms are generated by alternative splicing of mutually exclusive exons and differ in that PKM1 mRNA contains exon 9 and lacks exon 10, whereas PKM2 mRNA includes exon 10 and lacks exon 9. RT-PCRs were carried out with primers designed in exon 8 and 11, to yield a 218 bp PKM1 mRNA and a $183 \mathrm{bp}$ PKM2 mRNA. This allows the quantitative assay of each isoform and the identification of the PCR amplicon by digestion with StuI, which recognizes an AGGCT sequence in exon 10 and yields a 149 and a 34 bp product in PKM2.

TABLE 1 | Primers for Q-PCR used in (A) human samples and (B) murine samples.

\section{A. Primers for Q-PCR used in human samples}

IL1B FWD

IL1B REV

IL10 FWD

IL10 REV

IL12A FWD

IL12A REV

IL12B FWD

IL12B REV

IL23A FWD

IL23A REV

TNFA FWD

TNFA REV

DDIT3/CHOP FWD

DDIT3/CHOP AS

PKM1 FWD

PKM1 REV

PKM2 FWD

PKM2 REV

XBP1 FWD

XBP1 REV

GFPT1 FWD

GFPT1 REV

GAPDH FWD

GAPDH REV
5'-ATGATGGCTTATTACAGTGGCAA-3'

5'-GTCGGAGATTCGTAGCTGGA-3' 5'-GAGAACAGCTGCACC CAC ПT-3'

5'-GGCCTTGCTCTTGTT TTCAC-3'

5'-GAGGCCTGTTTACCATTGGA-3'

5'-TCAAGGGAGGATIITGTGG-3'

5'-CATGGGCCTTCATGCTATाT-3'

5'-TाT GCATTG TCAGGTITCCA-3'

5'-CATGGGCCTTCATGCTATाT-3

5'-TाT GCATTG TCAGGTTTCCA-3'

5'-GTTGTAGCAAACCCTCAAGC-3' 5'-TTGAAGAGGACCTGGGAGTA-3' 5'-GCAGAGATGGCAGCTGAGTC-3' 5'-AGCCAAGCCAGAGAAGCAGGGT-3'

5'-GCATCATGCTGTCTGGAGAA-3'

5'-AACTATCAAAGCTGCTGCTA-3'

5'-CTATCCTCTGGAGGCTGTGC-3'

5'-ACGATTATGGCCCCACTGCA-3'

5'-TAAGACAGCGCTTGGGGATGGA-3'

5'-ATACCGCCAGAATCCATGGGGA-3'

5'-AATGCTGGTCCTGAGATTGG-3'

5'-TTGATाTCAGTGCCCCTTC-3'

5'-GTCAGTGGTGGACCTGACCT-3' 5'-AGGGGAGATTCAGTGTGGTG-3'

B. Primers for Q-PCR used in murine samples

\begin{tabular}{ll}
\hline sXbp1 FWD & 5'-AAGAACACGCTTGGGAATGG-3' \\
sXbp1 REV & 5'-CTGCACCTGCTGCGGAC-3' \\
Ddit3 FWD & 5'-GTCCCTAGCTTGGCTGACAGA-3' \\
Ddit3 REV & 5'-TGGAGAGCGAGGGCTTG-3' \\
II23a FWD & 5'-AGGGAACAAGATGCTGGAT-3' \\
IL23aREV & 5'-AGTAGATTCATATGTCCCGCT-3'
\end{tabular}




\section{Western Blotting}

Proteins were separated by electrophoresis in SDS/PAGE and transferred to nitrocellulose membranes. The membranes were used for the immunodetection of COX-2 (Santa Cruz sc-1745), CHOP (Santa Cruz sc-793), elongation initiation factor $2 \alpha$ (eIF2 $\alpha$, Cell Signaling \#5324), P-Y705-STAT3 (Cell Signaling \#9131), STAT3 (Cell Signaling \#9132), PKM2 (Cell Signaling \#3198S), IL-1 $\beta$ (Cell Signaling \#12242), histone H3 (abcam ab1791), acetylK9-histone H3 (Millipore \#4-1003;), P-S10-histone H3 (Millipore \#04-817), spliced XBP1 (sXBP1; BioLegend \#619501), ATF6 (abcam ab11909), HIF1 $\alpha$ (Novus Biologicals NBP1-19779), and P-S52-eIF2 $\alpha$ (Invitrogen \#44-728G). For immunoblots directed to assay nuclear proteins, the nuclear extracts were obtained by using a nuclear extract kit (Active Motif). Anti-TATA-boxbinding protein (Diagenode TBPCSH-100) and anti-histone $\mathrm{H} 3$ $\mathrm{Ab}$ were used for protein load control.

\section{Laser-Scanning Confocal Fluorescence Microscopy}

Dendritic cells were seeded on poly-lysine-coated glass coverslips for $12 \mathrm{~h}$ and then stimulated with zymosan particles. Cells were fixed with $10 \%$ formaldehyde in PBS and stained with anti-HIF1 $\alpha$ $\mathrm{Ab}$ or anti-PKM2 Ab and goat anti-rabbit IgG Ab labeled with Alexa-Fluor ${ }^{\circledR} 480$. The coverslips were observed by laser-scanning confocal fluorescence microscopy using a Leica TCS SP5 apparatus equipped with a white-light laser and a Leica 63PL APO NA 1.40 oil immersion objective. Image analysis and subcellular colocalization fluorograms were generated and analyzed using the Leica confocal software package LAS AF Lite and Adobe Photoshop CS5.1 software.

\section{Real-time RT-PCR}

Total RNA was obtained by TRIzol/chloroform extraction and used for RT reactions. Cycling conditions were adapted to each set of primers. GAPDH was used as a housekeeping gene to assess the relative abundance of the different mRNA using the comparative cycle threshold method. The procedure was used to assay CHOP, IL10,IL23A, IL12A, IL12B, and IL1B mRNA. The sequences of the primers are shown in Table 1.

\section{Assay of Arachidonate Metabolites by Reversed Phase Ultraperformance Liquid Chromatography (UPLC) and Electrospray Ionization Quadrupole Time-of-Flight Mass Spectrometry (MS)}

Lipids were extracted into ethanol from cell supernatants, eluted in methanol using Strata ${ }^{\mathrm{TM}}$ C-18E SPE cartridges (Phenomenex ${ }^{\circledR}$ ), and evaporated to dryness under $\mathrm{N}_{2}$. The chromatographic separation was conducted in an Acquity ${ }^{\mathrm{TM}}$ UPLC System equipped with an Acquity UPLC $^{\circledR}$ BEH C18, $1.7 \mu \mathrm{m}, 2.1 \times 100 \mathrm{~mm}$ column (Waters). The chromatographic column was directly interfaced into the electrospray ionization source of a mass spectrometer (SYNAPT HDMS G2) from Waters. MS analysis was performed in negative ion mode using a $\mathrm{MS}^{\mathrm{E}}$ method that allows simultaneous detection of analytes through a low energy function (full

scan) and a high energy function (collision energy) with ion partial fragmentation, as reported (31).

\section{Chromatin Immunoprecipitation (ChIP)}

\section{Assay}

Chromatin immunoprecipitation assays were conducted with $\mathrm{Ab}$ against P-T71-ATF2 (Cell Signaling \#9221), ATF4 (Santa Cruz sc-7583), C/EBP $\beta$ (Santa Cruz sc-150), and sXBP1 as previously reported (21). Briefly, cells were stimulated and then washed twice with PBS and fixed with $1 \%$ formaldehyde. Cross-linking was terminated by $0.125 \mathrm{M}$ glycine. Crude nuclear extracts were collected by microcentrifugation and resuspended in a lysis buffer containing a high salt concentration. Chromatin sonication was carried out using a Bioruptor device from Diagenode. The chromatin solution was precleared by adding Protein A/G PLUS-Agarose for $30 \mathrm{~min}$ at $4^{\circ} \mathrm{C}$ under continuous rotation. After elimination of the beads, $\mathrm{Ab}$ was added for overnight incubation at $4^{\circ} \mathrm{C}$, and then Protein A/G PLUS-Agarose was added and incubated for an additional period of $2 \mathrm{~h}$ at $4^{\circ} \mathrm{C}$. Beads were harvested by centrifugation at $4,000 \mathrm{~g}$ and sequentially washed with lysis buffer high salt, wash buffer, and elution buffer. Cross-links were reversed by heating at $67^{\circ} \mathrm{C}$ in a water bath, and the DNA bound to the beads isolated by extraction with phenol/chloroform/isoamylalcohol. Irrelevant $\mathrm{Ab}$ and sequences of the $I L 12 \mathrm{~A}$ promoter were used as control of binding specificity. The sequences of the primers are shown in Table 2. Results are expressed as percentage of input.

\section{Statistical Analysis}

Data are represented as the mean \pm SEM and were analyzed with the Prism 4.0 statistical program (GraphPad Software). Comparison between experimental groups was carried out using the two-tailed Student's $t$-test and ANOVA. Differences were considered significant for $p<0.05$.

TABLE 2 | Primers used for ChIP.

IL12A Control FWD

IL12A Control REV

IL23A X2-Box-C/EBP FWD

IL23A X2-Box-C/EBP REV

IL23A X2-Box medial FWD

IL23A X2-Box medial REV

IL23A X2-Box distal FWD

IL23A X2-Box distal REV

IL23A CHOP-C/EBP proximal FWD IL23A CHOP-C/EBP proximal REV

IL23A CHOP-C/EBP FWD

IL23A CHOP-C/EBP distal REV

IL23A C/EBP $\beta$ FWD

IL23A C/EBP $\beta$ REV

IL23A CRE FWD

IL23A CRE REV

IL23A ATF2 FWD

IL23A ATF2 REV

GFPT1 $\times 2$-Box FWD

GFPT1 $\times 2$-Box REV

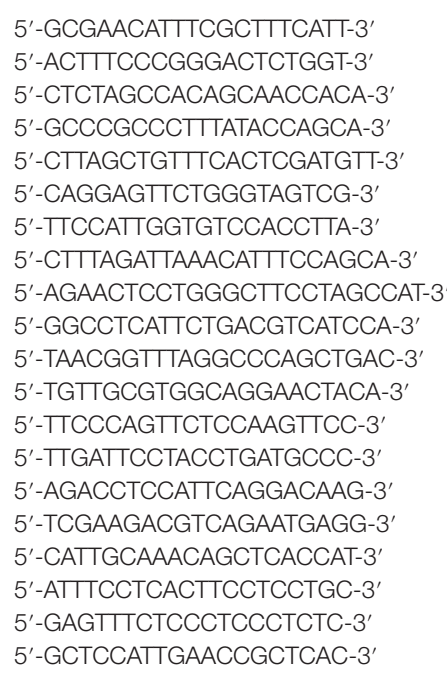

ChIP, chromatin immunoprecipitation. 


\section{RESULTS}

\section{Metabolic Profile of DCs}

Stimulation of DCs with LPS produced a concentrationdependent increase of the ECAR that could be detected immediately after the addition of the stimuli in the XF Mito Stress Test (Figure 1A, right panel). Assessment of the OCR showed stable values in the case of LPS (Figure 1B) and a tendency to increase in the case of zymosan that did not reach statistical significance (Figure 1C). The ECAR values were somewhat higher in response to zymosan than in the case of LPS and showed a more reproducible pattern of response (Figure 1C). These results are consistent with a fast and lasting increase of glycolysis upon a wide range of PAMPs concentrations, as judged from the net decrease of the OCR/ECAR ratio (Figures 1B,C, bottom panels).

\section{Mechanisms Underlying Metabolic Rewiring}

One of the mechanisms promoting glycolysis in the presence of normoxia, usually termed Warburg effect or aerobic glycolysis, is the activation of HIF1 by the stabilization of its HIF $1 \alpha$ subunit. This explains the induction of glycolytic enzyme expression, which in macrophages depends on the formation of a complex with pyruvate kinase M2 (PKM2) (32) that translocates to the nucleus and regulates the expression of proglycolytic enzymes (33). PKM2 may act as a protein kinase that phosphorylates STAT3 at Y705 (34) and histone H3 (35). This explains a positive feedback loop between HIF1 and STAT3 since Y705-STAT3 activates HIF1 $\alpha$ transcription $(36,37)$. In a previous study, we observed that both zymosan and LPS are robust activators of Y705-STAT3 phosphorylation through the induction of secondary mediators (38). In keeping with that report, the assay of P-Y705-STAT3 in nuclear extracts showed a time-course compatible with its involvement in HIF1 $\alpha$ expression (Figure 2A). As a correlate of enhanced transcriptional activity, zymosan induced global phosphorylation of S10-histone $\mathrm{H} 3$ and acetylation of K9-histone H3 (Figure 2B). The nuclear translocation of HIF1 $\alpha$ was confirmed in immunofluorescence confocal microscopy studies (Figure 2C). The preferential expression of PKM2 was confirmed by Western blot (Figure 2D) and by immunofluorescence confocal microscopy, which showed the enzyme in the nuclei and in cytoplasm areas surrounding phagocytosed zymosan particles (Figure 2E), as well by analysis of its mRNA by RT-PCR. Assays with sets of primers that generate products distinguishable by the number of bp, showed a 149 and a $34 \mathrm{bp}$ product in PKM2 upon treatment with StuI, whereas the PKM1 amplicon was not digested (Figure 2F). Taken collectively, these data show the presence of P-Y705-STAT3 and HIF1 $\alpha$ in the nuclei of zymosan- and LPS-stimulated DCs, as well as a high expression of PKM2 protein. However, the temporal pattern of HIF1 $\alpha$ protein induction does not parallel the early changes of both OCR and ECAR, thus suggesting that other mechanisms may underlie the early rewiring of the bioenergetic profile of DCs, i.e., the association of hexokinase II with voltage-dependent anion channels in the outer mitochondrial membrane (39).
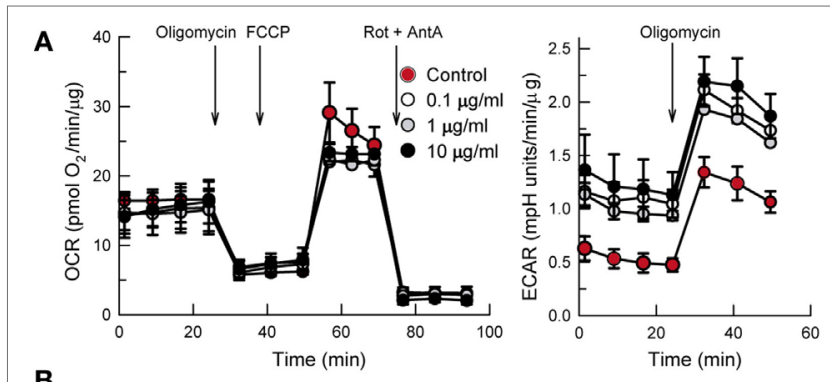

B
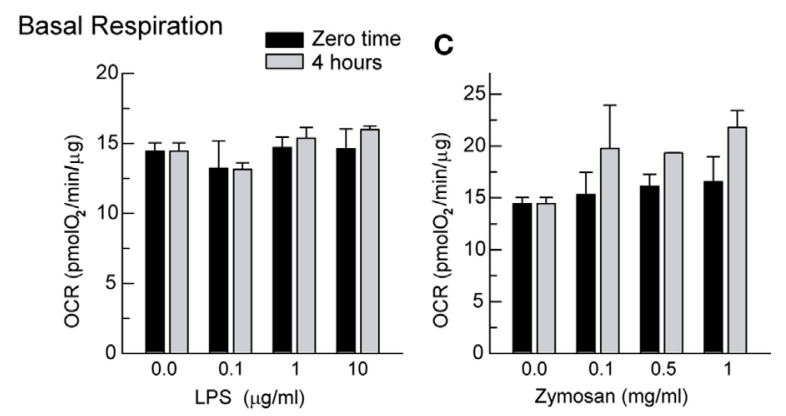

Basal ECAR
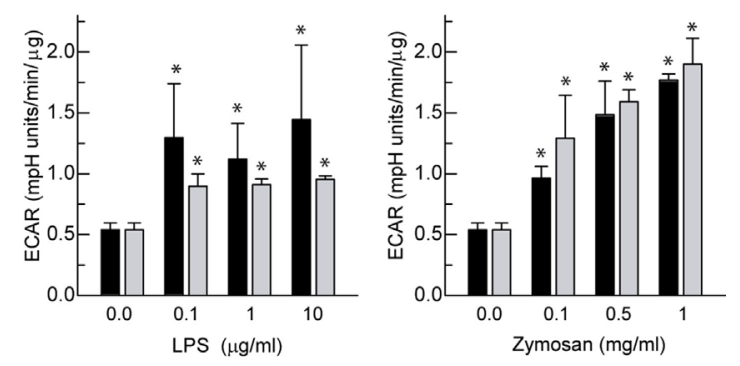

OCR/ECAR
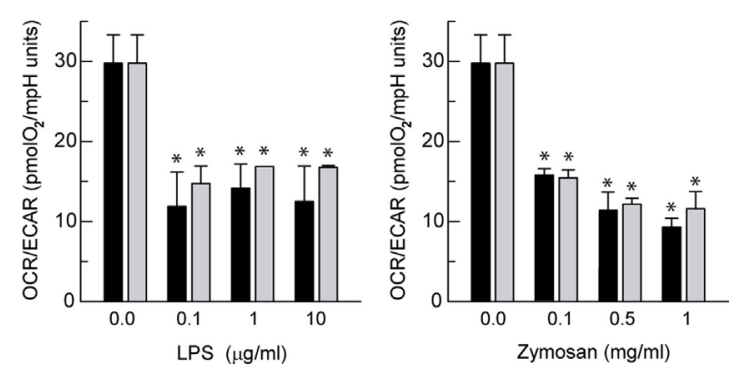

FIGURE 1 | Effect of lipopolysaccharide (LPS) and zymosan on the bioenergetics of dendritic cells (DCs). (A) Recordings of the XF Mito Stress Test Kit protocol obtained in the presence of different concentrations of LPS. (A-C) DCs were stimulated for the times indicated in XF Seahorse assay medium in the presence of different concentrations of LPS and zymosan and then immediately adhered to poly-ornithine-coated plates for the assay of extracellular acidification rate (ECAR) and oxygen consumption rate (OCR). Results represent mean \pm SEM of three independent experiments. ${ }^{*} p<0.05$ as compared to DCs maintained in the absence of stimuli.

\section{Effect of Glucose Starvation and 2-DG on Cytokine Expression}

Given the increases of the ECAR induced by PAMPs, lactate levels were assayed. Lactate production was strongly blocked in glucose-starved cells and to a lesser extent in the presence 


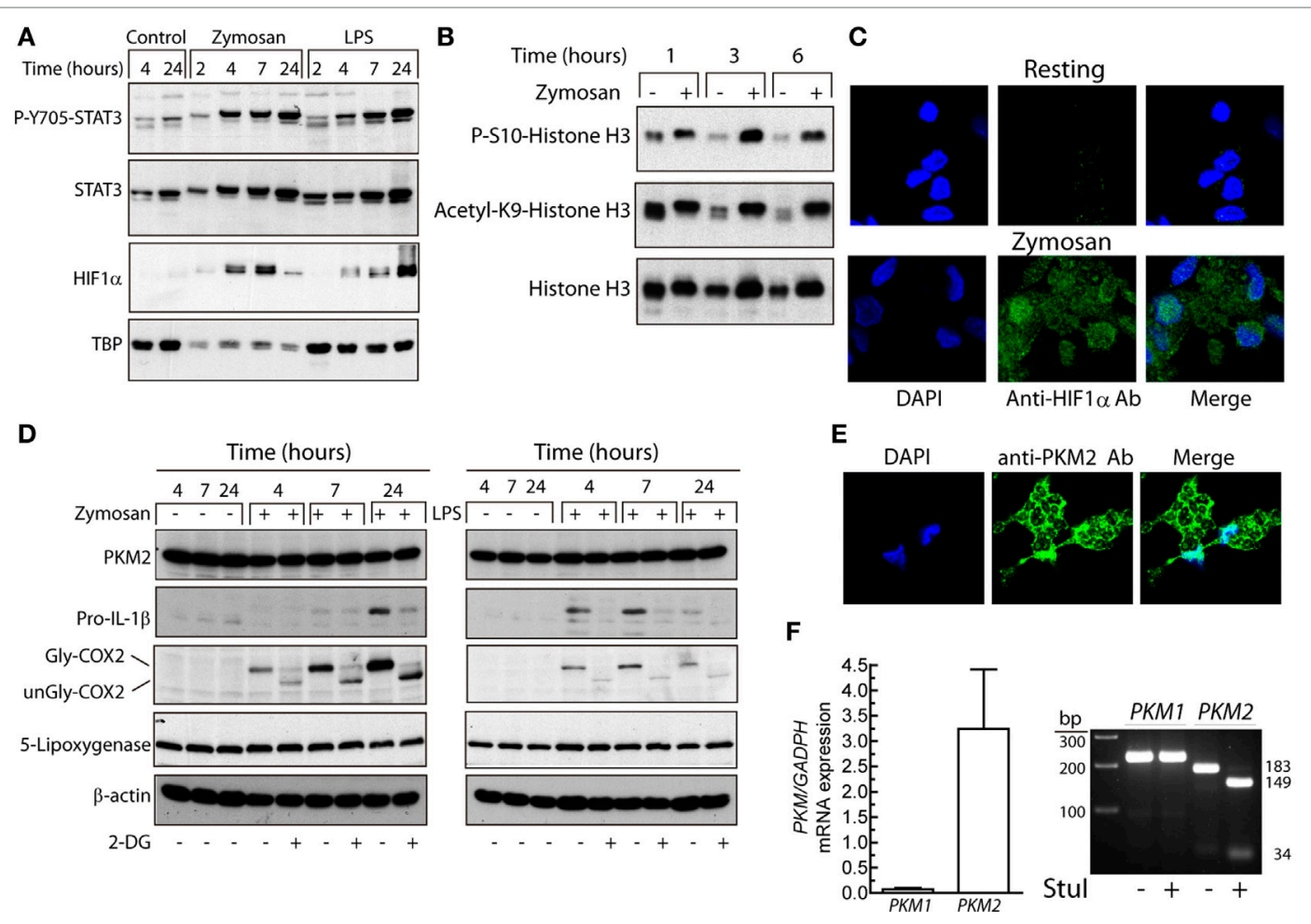

FIGURE 2 | Effect of dendritic cells (DCs) stimulation on Y705-STAT3 phosphorylation and HIF1 $\alpha$ protein expression. (A,B) Nuclear fractions were used for the assay of STAT3 phosphorylation, HIF1 $\alpha$ protein, and S10-phosphorylation and K9-acetylation of histone H3. (C) Nuclear translocation of HIF1 $\alpha$ assayed by laser-scanning confocal immunofluorescence microscopy in resting and zymosan-treated DCs. (D) The expression of pyruvate kinase M2 (PKM2), pro-IL-1 $\beta$, cyclooxygenase 2 (COX-2), and 5-lipoxygenase was immunodetected in DCs stimulated with zymosan and lipopolysaccharide (LPS) for different times in DCs preincubated for $1 \mathrm{~h}$ in the presence or absence of $10 \mathrm{mM}$ 2-deoxy-D-glucose (2-DG) prior to the addition of the pathogen-associated molecular patterns (PAMPs). (E) Location of PKM2 to cytoplasm and nucleus assayed by laser-scanning confocal immunofluorescence microscopy in DCs stimulated with zymosan. (F) Confirmation by RT-PCRs and selective digestion by Stul of the PKM2 amplicon of the predominant expression of PKM2. TBP indicates TATA-box-binding protein. Gly indicates glycosylated and unGly, unglycosylated.

of $10 \mathrm{mM}$ 2-DG (Figure 3A). Consistent with seminal studies on non-opsonic phagocytosis, in which 2 -DG did not reduce zymosan uptake even when ATP production was blocked $(40,41)$, DCs showed robust phagocytosis in the presence of 2-DG and also exhibited a robust ability to release arachidonic acid (Figure 4), thus suggesting that the effect of 2-DG cannot be explained by an effect on the earliest steps of DCs activation. Unexpectedly, the mRNA levels of various cytokines showed notable differences under glucose-limiting conditions and in the presence of 2-DG. The most striking effect was observed on the induction of $I L 23 A$, which increased $\sim 20$-fold $24 \mathrm{~h}$ after stimulation (Figure 3B). The assay of IL-23 protein showed a net increase in the case of LPS, but not in the case of zymosan (Figure 3C). A likely explanation is that the high production of IL-23 protein induced by zymosan under these conditions could not increase because, unlike LPS, zymosan triggers low transcription of the gene encoding the p40 chain (IL12B), which is a limiting step for the production of this heterodimeric cytokine. The assay of other cytokines showed prominent changes in response to LPS, including an increase of IL12A mRNA and a reduction of IL10 and $I L 1 B$ mRNA. The expression of pro-IL-1 $\beta$ was also blunted in the presence of 2-DG (Figure 2D). Given that these findings could not be explained by a simple blockade of glucose metabolism, alternative mechanisms were postulated, focusing on the effect of 2-DG on mannose metabolism, N-glycosylation reactions, and the possible activation of the UPR as a result of potential protein misfolding. Consistent with this hypothesis, stimulation of DCs with zymosan and LPS in the presence of 2-DG induced robust splicing of the $X B P 1 \mathrm{mRNA}$ (Figure 3D), whereas the sole addition of 2-DG or PAMP did not. In sharp contrast, $X B P 1$ splicing was not observed in DCs starved of glucose for up to $18 \mathrm{~h}$ and stimulated with PAMPs (not shown). Given the prominent enhancement of aerobic glycolysis induced by PAMPs and a recent report underscoring that this process reduces the supply of fructose-6-phosphate to glutamine-fructose-6-phosphate transaminase 1 (GFPT1), the enzyme that transfers the amino group of L-glutamine to yield glucosamine-6-phosphate for $\mathrm{N}$-glycan biosynthesis (42), our data point out that the coincidental inhibition of mannose metabolism by $2-\mathrm{DG}$ and of the hexosamine biosynthetic pathway by aerobic glycolysis show optimal conditions for $\mathrm{N}$-glycosylation blockade. XBP1 splicing was observed after $2 \mathrm{~h}$ of incubation (Figure 3E) and was blunted by $1 \mathrm{mM}$ mannose and the inhibitor of the endonuclease activity of IRE1 $\alpha$ MKC8866 (Figure 3F). Notably, these treatments also inhibited the effect of 2-DG on the induction of IL23A elicited by zymosan (Figure 3G), whereas this effect was less definite in 
A
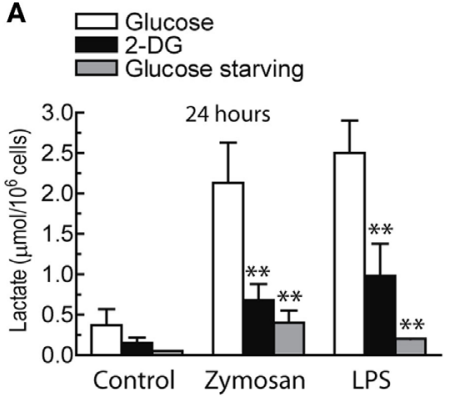

C

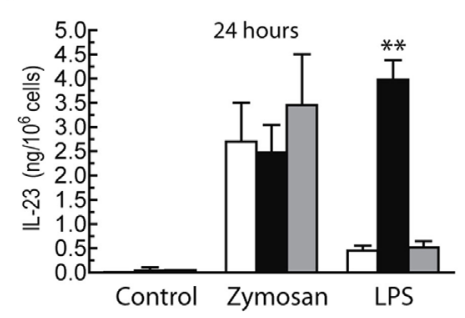

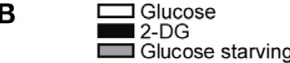
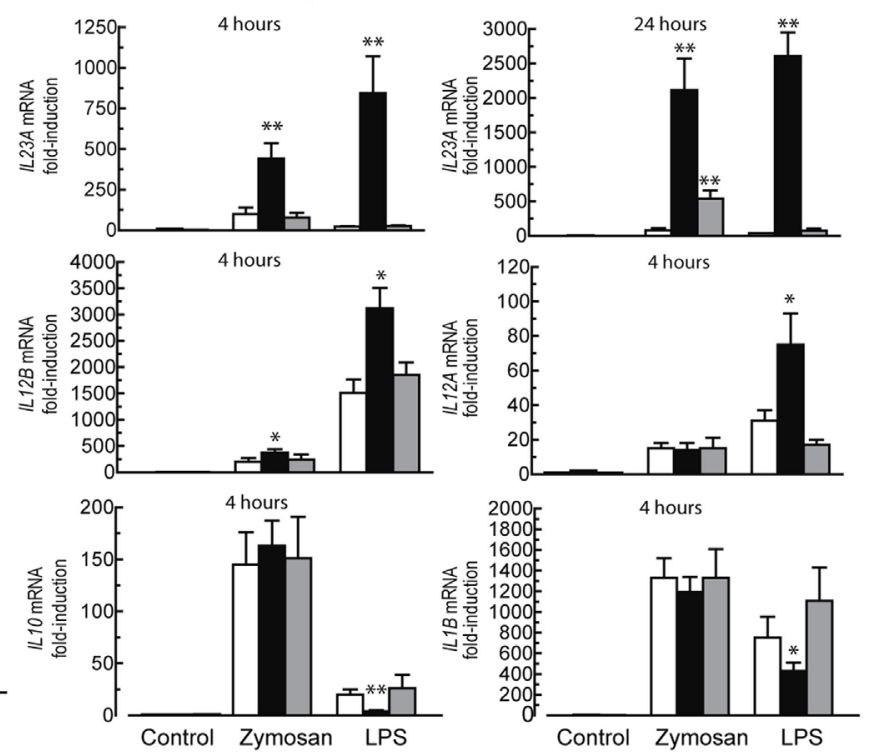

D

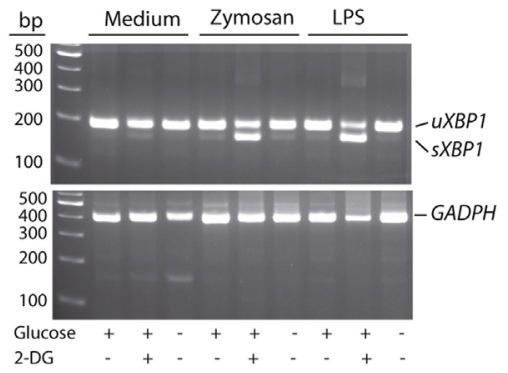

$\mathbf{F}$

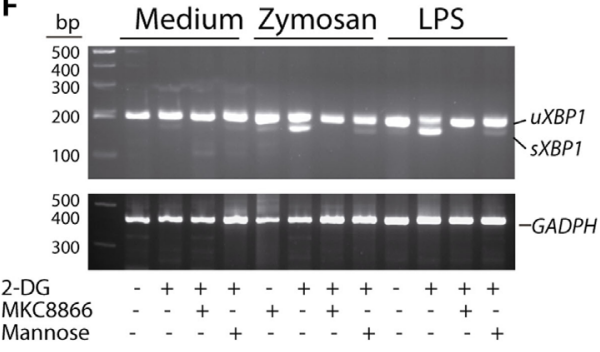

E

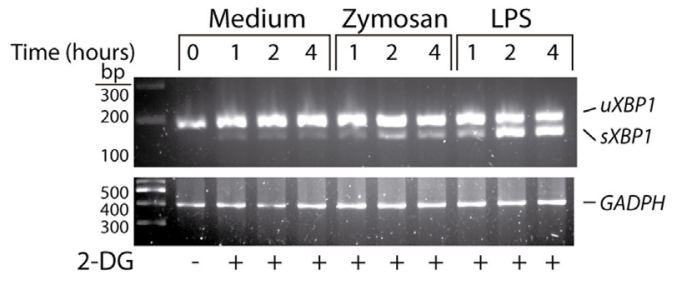

G
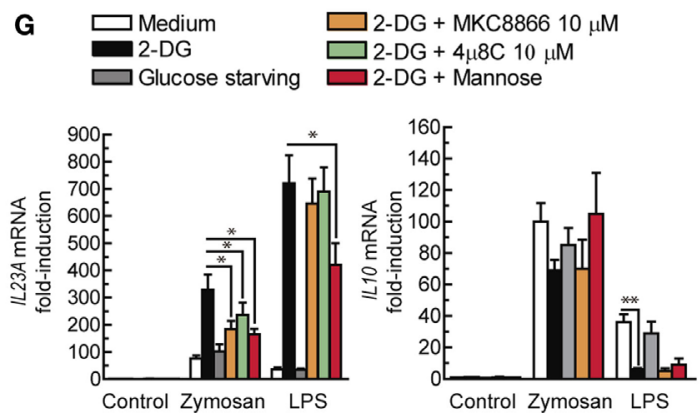

FIGURE 3 | Effect of 2-deoxy-D-glucose (2-DG) on lactate production, cytokine expression, and XBP1 splicing. (A) Production of lactate by dendritic cells (DCs) in the presence and absence of $11.1 \mathrm{mM}$ glucose and in the presence of $10 \mathrm{mM}$ 2-DG. (B) Effect of 2-DG or glucose starvation on the expression of the mRNA of different cytokines in DCs stimulated with $1 \mathrm{mg} / \mathrm{mL}$ zymosan and $10 \mu \mathrm{g} / \mathrm{mL}$ lipopolysaccharide (LPS) for the times indicated. (C) Effect of 2-DG on the production of IL-23 protein and on (D) XBP1 mRNA splicing. (E) Time course of XBP1 mRNA splicing and (F) effect of $1 \mathrm{mM}$ mannose and $10 \mu \mathrm{M}$ MKC8866 on the splicing of XBP1 mRNA elicited by 2-DG. (G) Effect of mannose and inositol-requiring protein $1 \alpha$ (IRE1 $\alpha$ ) endonuclease inhibitors on the mRNA expression of IL23A and IL10. Results show mean \pm SEM of 5 to 10 experiments in the mRNA assays. XBP1 mRNA splicing assays have been carried out at least twice. sXBP1 stands for spliced X-box binding protein 1, uXBP1 stands for unspliced XBP1 $\left({ }^{\star} p<0.05,{ }^{* *} p<0.01\right)$.

the case of LPS. The effect of $2-\mathrm{DG}$ on $I L 10$ mRNA induction was less sensitive to mannose and IRE1 $\alpha$ inhibitors (Figure 3G, right panel). These data suggest that the effect of 2-DG on IL23A expression can be explained by interference with mannose metabolism and associated with the activation of the UPR, whereas the effect on IL10 mRNA expression seems dependent on other mechanisms.

\section{Effect of Lactate}

Since the distinct effects observed on IL23A and IL10 mRNA expression elicited by $2-D G$ could not be explained by a sole mechanism and given that 2-DG reduced lactate production (Figure 3A) and blocked pro-IL-1 $\beta$ expression (Figure 2D), the effect of $2-\mathrm{DG}$ on the lactate/HIF1 route was addressed. $2-\mathrm{DG}$ inhibited the expression of HIF1 $\alpha$ induced by zymosan 


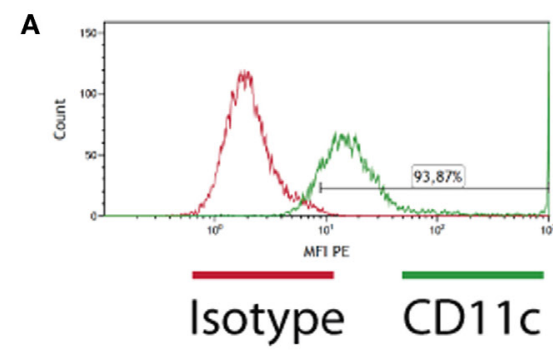

B
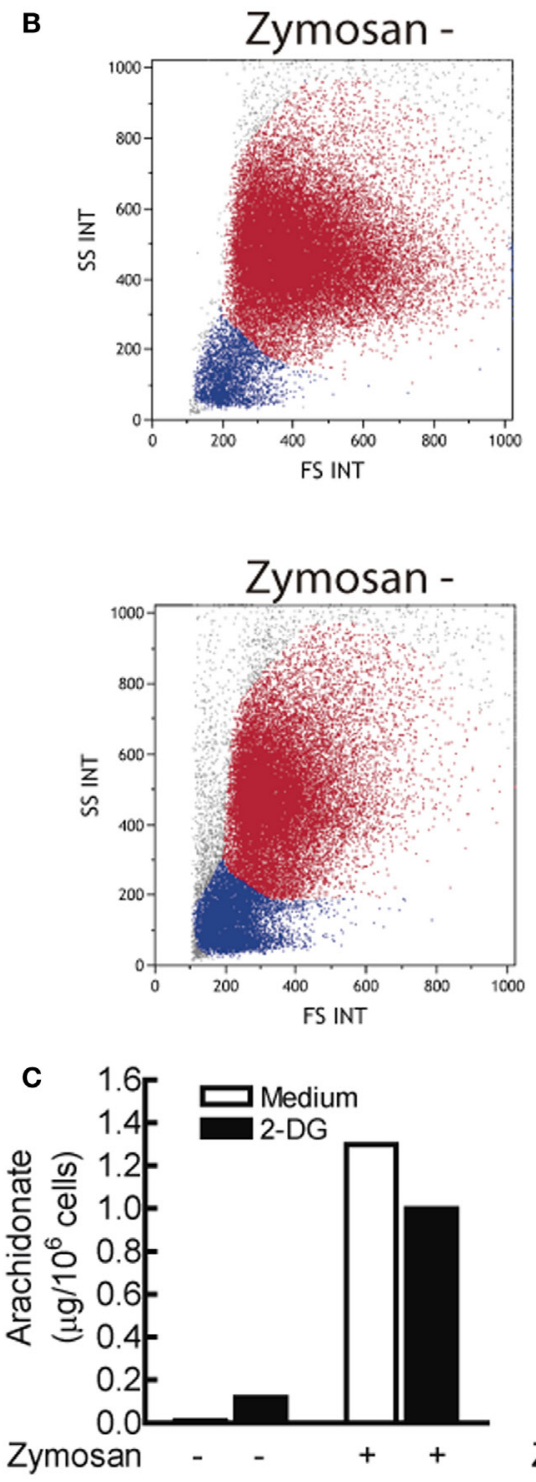

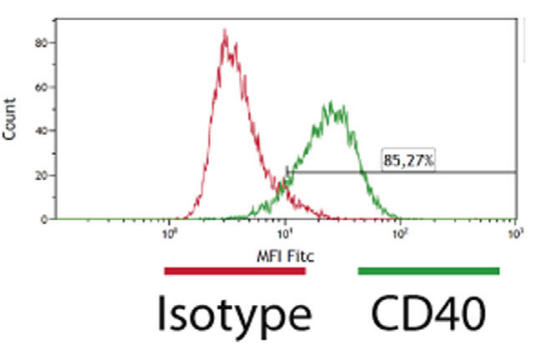

2-DG -

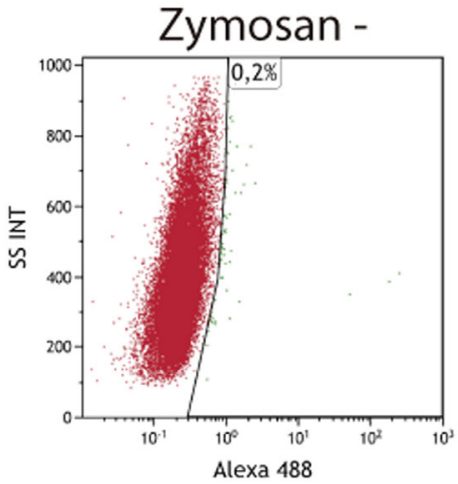

2-DG +
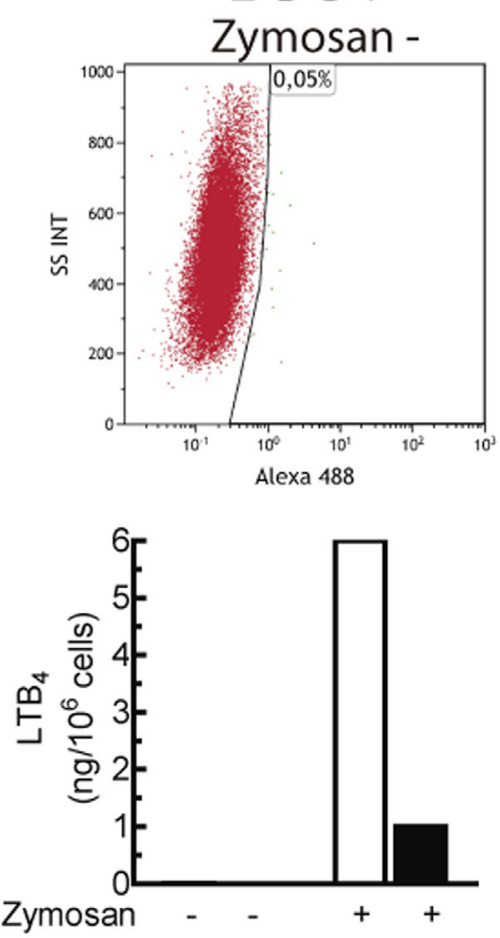
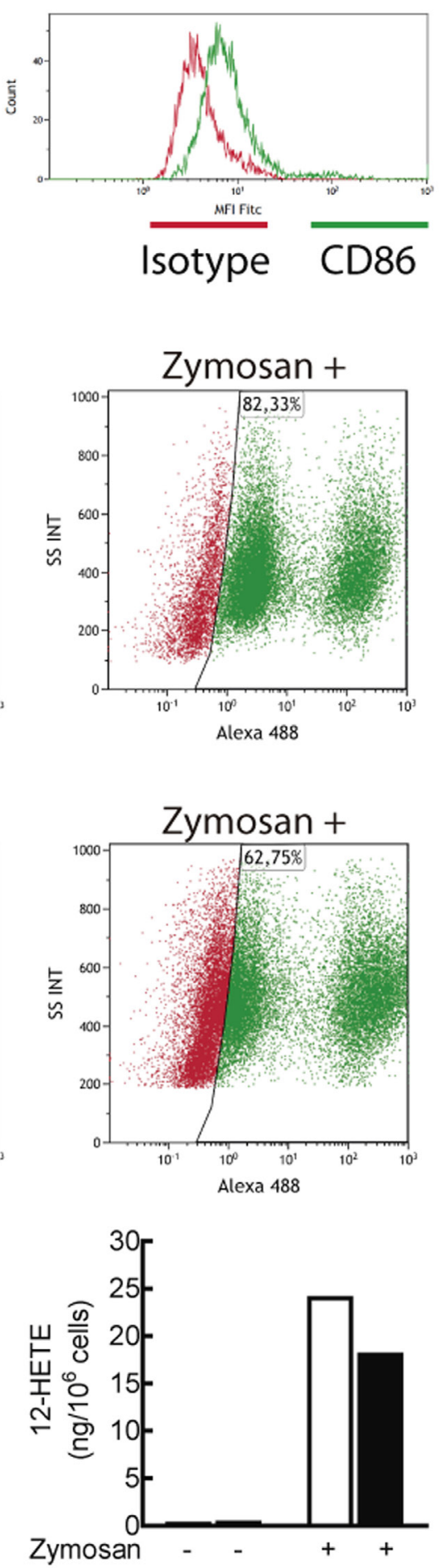

FIGURE 4 | Characterization of the dendritic cell (DCs) population and effect of 2-deoxy-D-glucose (2-DG) on zymosan phagocytosis and arachidonate release. (A) Expression of CD11c, CD40, and CD86 in monocyte-derived DCs. (B) Effect of 2-DG on the phagocytosis of Alexa Fluor ${ }^{\circledR 88}$ dye-conjugated zymosan particles. DCs were incubated in the presence and absence of $10 \mathrm{mM}$ 2-DG for 1 h. At the end of this period, Alexa Fluor ${ }^{\circledR} 488-{ }^{-c o n j u g a t e d ~ z y m o s a n ~ p a r t i c l e s ~ w e r e ~ a d d e d ~ a t ~}$ a concentration of three particles per DC, and then the uptake of zymosan particles was assayed by flow cytometry. The dot plots represent side scatter (SS) versus forward scatter (FS) intensities in the left panels, and SS intensity versus Alexa Fluor ${ }^{\circledR} 488$ green fluorescence in the middle and right panels. (C) DCs were stimulated with $1 \mathrm{mg} / \mathrm{mL}$ zymosan particles for $1 \mathrm{~h}$ in the presence and absence of 2-DG and the supernatants collected for the assay of the most abundant eicosanoids. $\mathrm{PGE}_{2}$ was not detected under these conditions. $\mathrm{LTB}_{4}$ indicates leukotriene $\mathrm{B}_{4}$. 
A

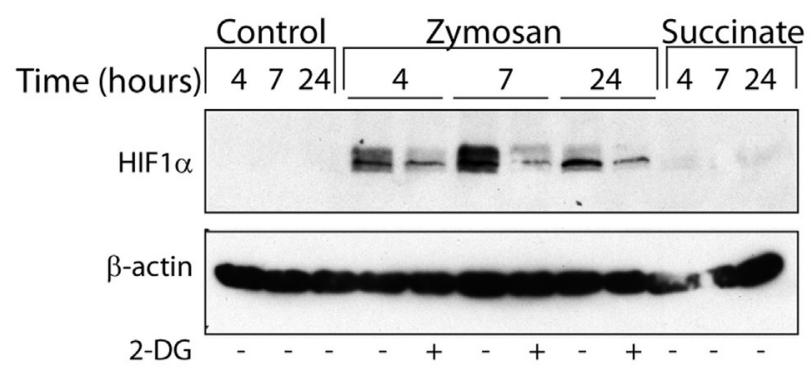

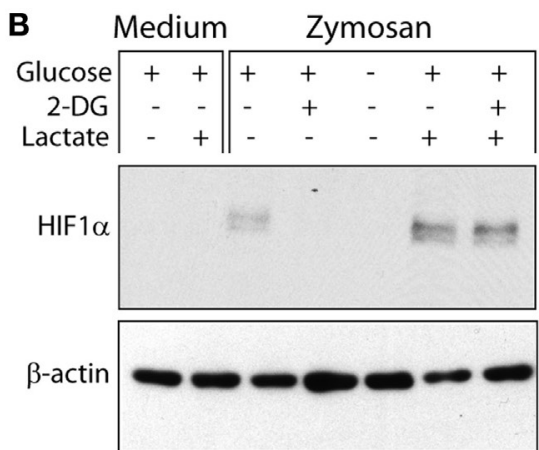

C

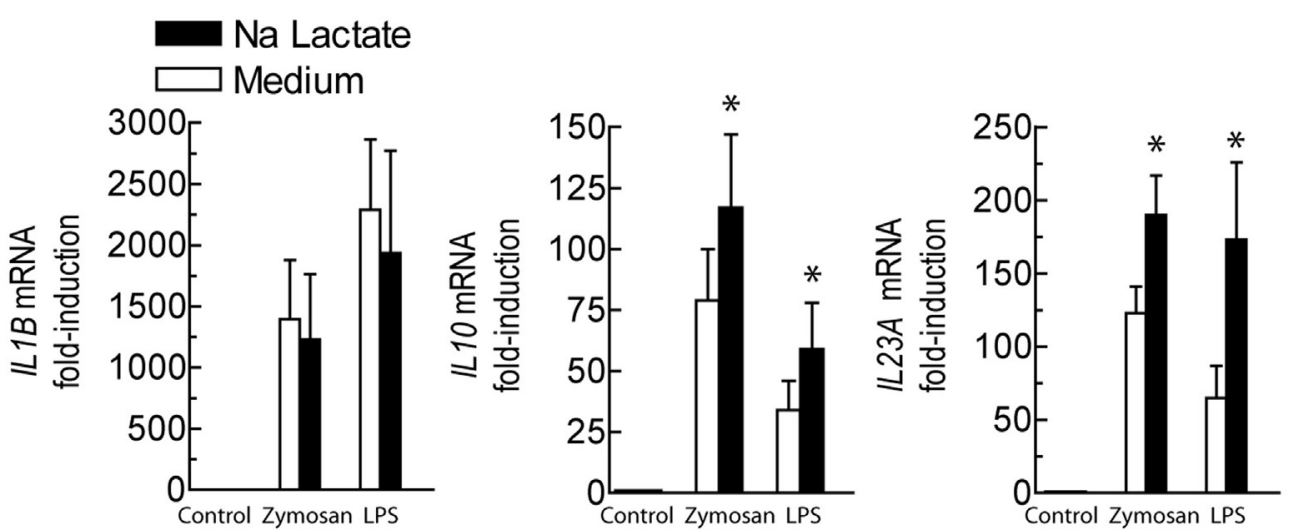

D
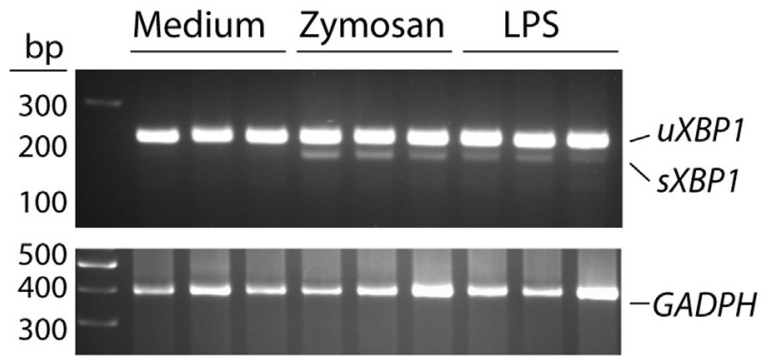

Na lactate $\quad-\quad+\quad-\quad+\quad-\quad+-$

Lactic acid $\quad-\quad-\quad+\quad-\quad+\quad-\quad+$

FIGURE 5 | Effect of lactate and 2-deoxy-D-glucose (2-DG) on the expression of HIF1 $\alpha$ protein and cytokines. (A) Effect of 2-DG on HIF1 $\alpha$ protein expression over different times of stimulation. (B) Dendritic cells (DCs) were stimulated for $4 \mathrm{~h}$ with $1 \mathrm{mg} / \mathrm{mL}$ zymosan in the presence and absence of 2-DG and $15 \mathrm{mM}$ lactate and the expression of HIF1 $\alpha$ protein assayed. (C) Expression of the mRNA of several cytokines in the presence and absence of $15 \mathrm{mM}$ sodium lactate. (D) Absence of X-box binding protein 1 (XBP1) splicing upon lactate and lactic acid treatment. Results show mean \pm SEM of three experiments in (C) and two assays of XBP1 mRNA splicing $\left({ }^{*} p<0.05\right)$.

(Figure 5A). An effect countered by lactate (Figure 5B). Stimulation of DCs in the presence of sodium lactate did not influence the expression of ILIB mRNA. In contrast, IL10 and IL23A mRNA expression showed a trend to increase (Figure 5C). Treatment with LPS and zymosan in the presence of either sodium lactate or lactic acid did not induce $X B P 1$ splicing (Figure 5D). These results confirm the involvement of the lactate/HIF1 system in pro-IL- $1 \beta$ expression and show that the effect of lactate on the mRNA expression of IL10 and IL23A is independent of XBPI splicing.

\section{Effect of L-Glutamine}

The effect of L-glutamine starvation was addressed given its involvement in both the hexosamine biosynthesis pathway and the tricarboxylic acid cycle. In addition, glutaminolysis contributes to restore metabolic homeostasis by enhancing the XBP1- and $\alpha$-ketoglutarate-dependent expression of GFPT1 (43). L-Glutamine removal induced a significant increase of lactate production in resting DCs after $24 \mathrm{~h}$ of incubation. In contrast, lactate levels were not significantly affected in the absence of L-glutamine after stimulation with zymosan, oligomycin or LPS 
(Figure 6A). IL10 mRNA expression showed a trend to reduction in the absence of L-glutamine that reached statistical difference at $24 \mathrm{~h}$ (Figure 6B). Stimulation of DCs in the absence of L-glutamine did not induce XBP1 splicing, although the effect of 2-DG was somewhat more prominent in the absence of L-glutamine (Figure 6C).

\section{The UPR Regulates IL23A trans-Activation}

Given the association of XBP1 splicing with the enhanced expression of IL23A mRNA, our experiments then focused on whether the UPR induced by other mechanisms showed similar results and the possible involvement of the PERK/eIF2 $\alpha / \mathrm{ATF} 4 / \mathrm{CHOP}$ branch of the UPR. P-S52-eIF2 $\alpha$ was detected to a low extent in resting DCs and did not increase upon 2-DG treatment and PAMPs stimulation (Figure 7A), in agreement with a recent report showing that LPS did not affect eIF2 $\alpha$ phosphorylation (44). The mRNA expression of DDIT3/CHOP was enhanced by $2-\mathrm{DG}$ and blunted by mannose in the presence of PAMPs (Figure 7B), thus suggesting that mannose may counter some of the mechanisms triggered by the stimuli by acting as a substrate for the formation of dolichol-linked oligosaccharide. Tunicamycin and thapsigargin induced similar effects to those elicited by 2-DG on IL23A and $I L 10$ mRNA expression (Figure 7C) as well as on XBP1 splicing (Figure 7D). Consistent with the inhibitory activity of 2-DG on COX-2 N-glycosylation (Figure 2D), tunicamycin, a robust inhibitor of this posttranslational modification, caused the same effect. In contrast, thapsigargin, which elicits the UPR via SERCA inhibition and does not interfere with $\mathrm{N}$-glycosylation reactions, failed to do so (Figure 7E). These data indicate that ER stress responses, rather than $\mathrm{N}$-glycosylation inhibition alone, underpin the cytokine signature induced by ER stressors. In keeping with previous results (21), the expression of CHOP protein was detectable in the nuclear fractions of resting DCs and showed a net trend to decrease after stimulation by zymosan (Figure 7F).
A

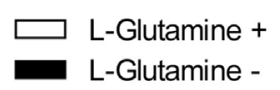

4 hours
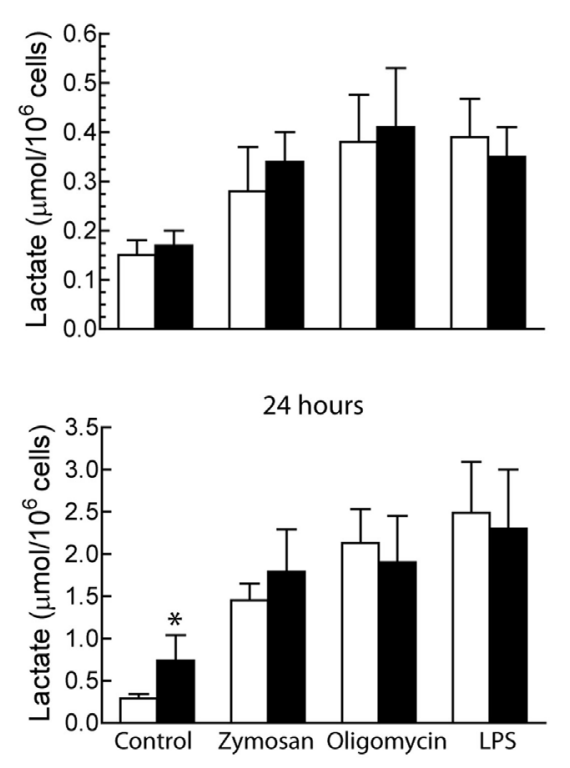

B
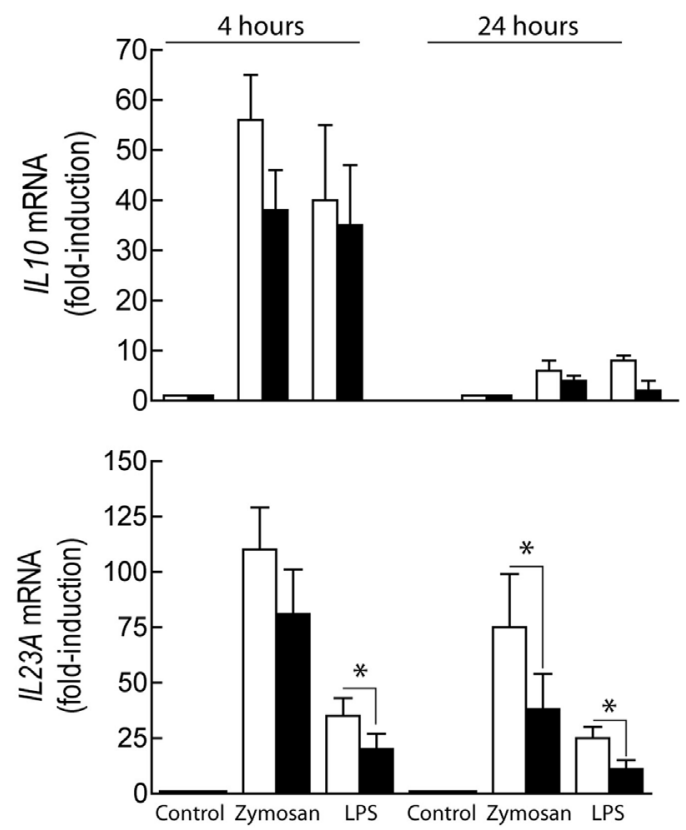

C
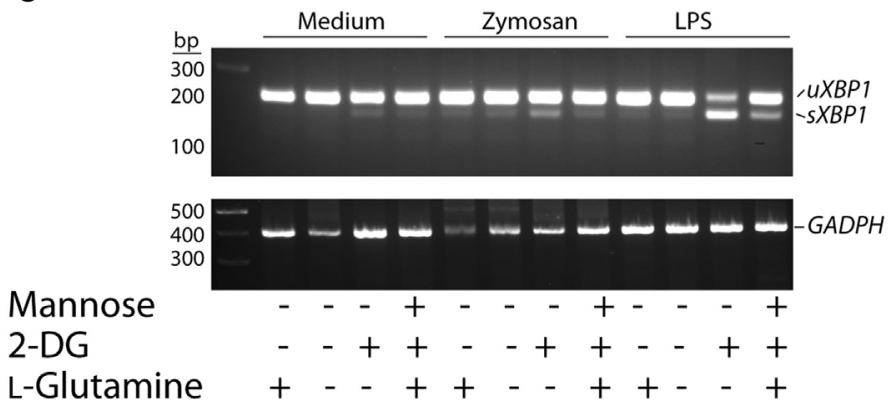

FIGURE 6 | Effect of L-glutamine starvation on cytokine production. (A-C) Dendritic cells (DCs) were maintained for the times indicated in the presence and absence of $4 \mathrm{mM}$ L-glutamine. At the end of these periods, the supernatant was collected for the assay of lactate (A) and the RNA extracted for the assay of the expression of cytokines (B) and X-box binding protein 1 (XBP1) splicing (C). Results show mean \pm SEM of three experiments $\left({ }^{*} P<0.05\right)$. 
A recent report has disclosed that PERK inhibition decreases UPR-dependent inflammation via attenuation of eIF $2 \alpha$ phosphorylation and reduction of the transcription of inflammatory genes as a result of translational repression (45). Consistent with this mechanism, PERK inhibition with GSK2606414 reduced the induction of DDIT3 and IL23A mRNA elicited by LPS in the presence of 2-DG. A similar result was obtained with the pyrazolebased PERK inhibitor AMG PERK 44, which has been found recently to lack the RIPK1-inhibitory effect recently disclosed for GSK2606414 (30). The effect of both compounds was less evident in zymosan-treated DCs and suggests a stimulus-dependent recruitment of the different arms of the UPR (Figure 7G). Consistent with the selectivity of GSK2006414 on the PERK route, XBP1 splicing was not inhibited (Figure $7 \mathbf{H}$ ). Stimulation with zymosan induced ATF6 cleavage to an extent higher than that produced by the sole addition of 2-DG, as well as a noticeable change in the mobility of full-length ATF6, most likely due to the underglycosylation of the protein before cleavage by site-1 proteases (46). Combination of zymosan with 2-DG did not enhance ATF6 cleavage and the effect of LPS was similar to the one elicited by the sole addition of 2-DG (Figure 7I).

Given that the trans-activation of IL23A induced by zymosan depends on at least NF- $\kappa$ B proteins and ATF2 (21), the interaction of P-T71-ATF2 with the IL23A promoter was assayed. The binding was partially inhibited in the presence of 2-DG, thus suggesting that other transcription factors might be engaged under these conditions (Figure 8A). The involvement of sXBP1 was then considered the leading hypothesis because of (i) the robust splicing
A

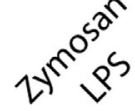

Time (hours) $0 \begin{array}{llllll}0 & 0 & 2 & 5 & 5 & 5\end{array}$
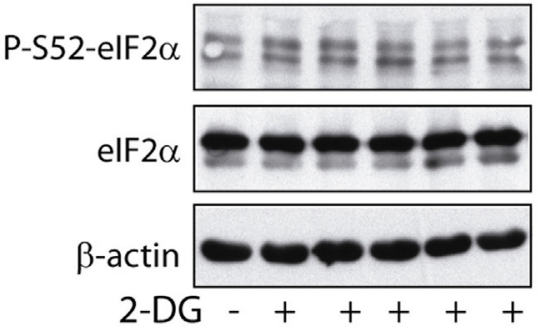

C

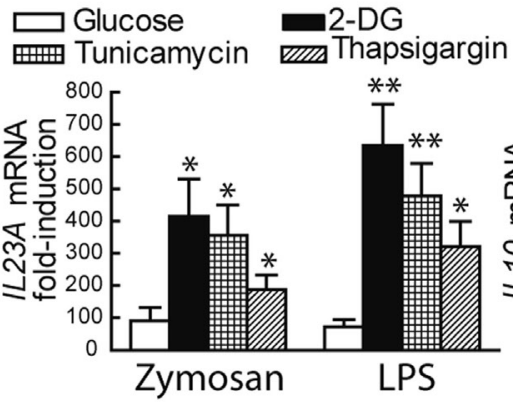

E
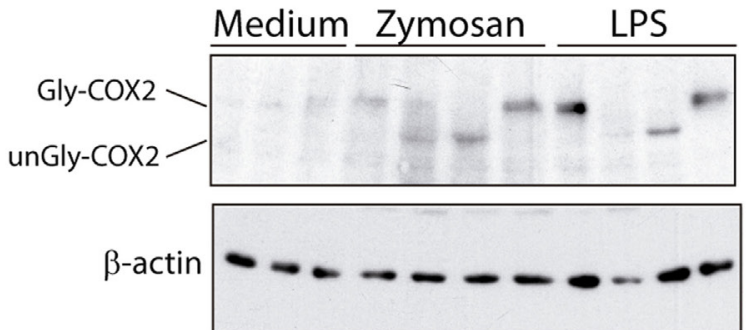

2-DG

Tunicamycin

Thapsigargin
B

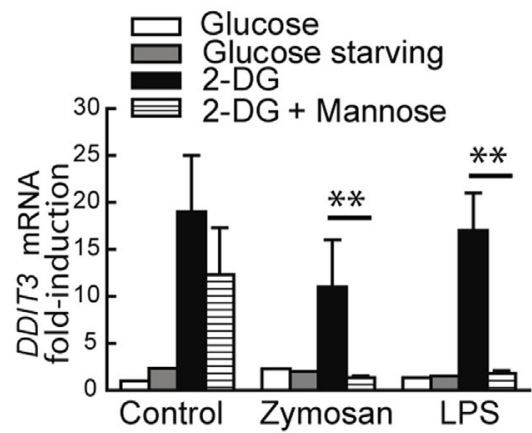

D
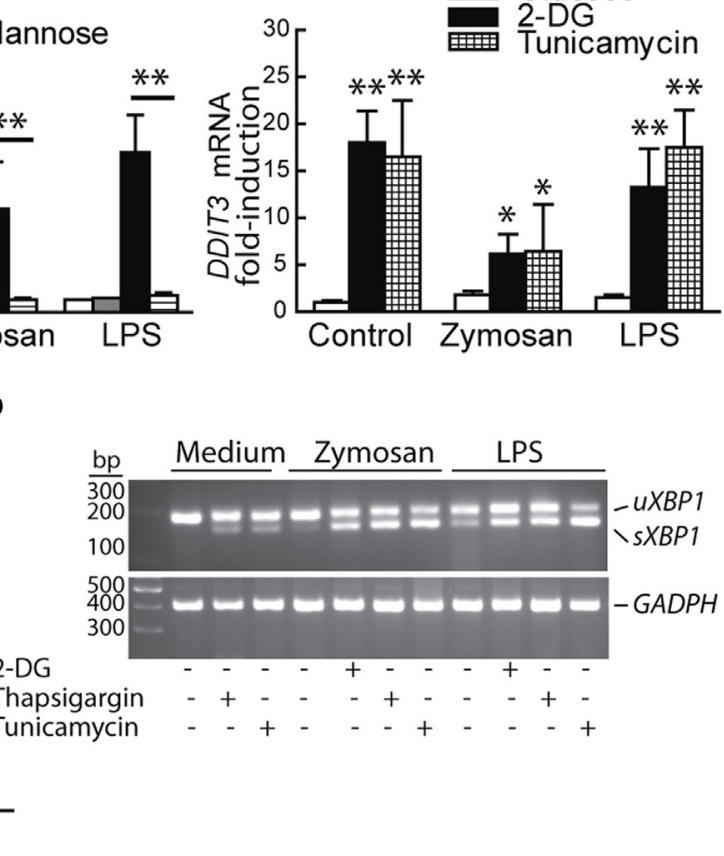

F Medium Zymosan LPS

FIGURE 7 | Continued 


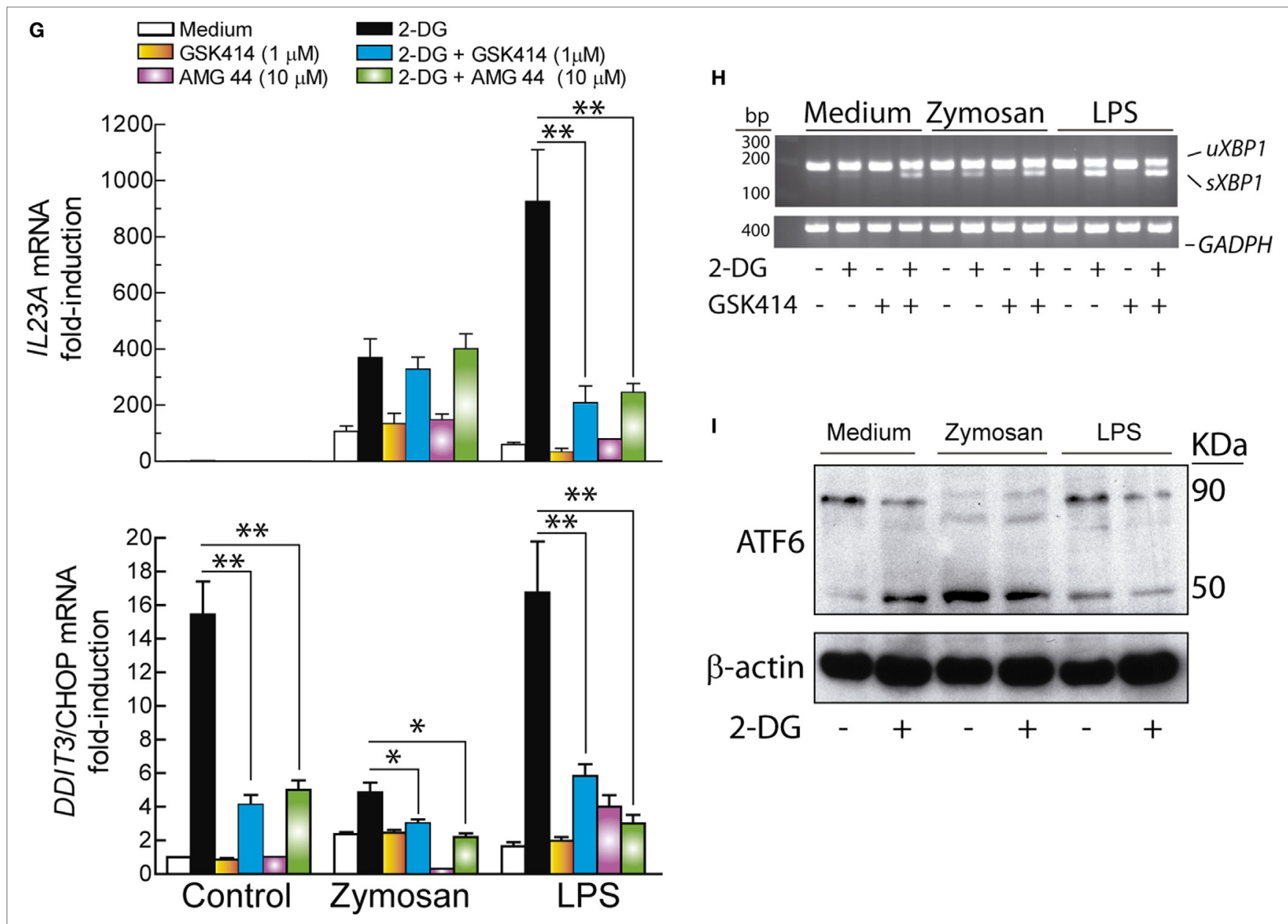

FIGURE 7 | Unfolded protein response (UPR) and cytokine expression. (A) Time course of elongation initiation factor $2 \alpha$ (elF2 $\alpha$ ) phosphorylation in dendritic cells (DCs) incubated with 2-deoxy-D-glucose (2-DG) and effect of zymosan and lipopolysaccharide (LPS) after preincubation with 2-DG for $1 \mathrm{~h}$ and stimulation for $4 \mathrm{~h}$. (B,C) DCs were stimulated with LPS or zymosan for $4 \mathrm{~h}$ in the presence of different additions and the mRNA of DD/T3/C/EBP homologous protein (CHOP), IL23A, and IL10 assayed. (D) Splicing of X-box binding protein 1 (XBP1) and unglycosylation of cyclooxygenase 2 (COX-2) (E) after $4 \mathrm{~h}$ of stimulation in the presence of the indicated additions. (F) Expression of CHOP protein in the nuclear extracts of DCs stimulated in the presence and absence of 2-DG. (G) Effect of $1 \mu \mathrm{M}$ GSK2606414 and $10 \mu \mathrm{M}$ AMG PERK 44 on IL23A and DDIT3/CHOP mRNA expression. The drugs were added 30 min prior to preincubation with 2-DG and the mRNA extracted after $4 \mathrm{~h}$ of incubation in the presence of the stimuli. (H) Lack of effect of GSK2606414 on XBP1 splicing. (I) Effect of 2-DG on ATF6 cleavage in DCs maintained for $1 \mathrm{~h}$ in the presence or absence of 2-DG and then stimulated for $1 \mathrm{~h}$ with zymosan or LPS. Experiments were carried out at least in duplicate $\left({ }^{*} p<0.05 ;{ }^{* *} p<0.01\right)$.

of $X B P 1$ and the effect of IRE1 $\alpha$ endonuclease inhibitors; (ii) the presence of three X-boxes in the IL23A promoter identified using the TRANSFAC database (21); and (iii) the role of XBP1 in the regulation of diverse targets exhibiting a wide array of sequence motifs $(12,47)$. sXBP1 protein was detected in the nuclear extract of DCs, but its expression did not show significant changes upon various treatments nor in the presence of MKC8866 (Figure 8B). 2-DG increased the binding of sXBP1 to the three X-boxes in the IL23A promoter (Figure 8C), which suggests the involvement of this transcription factor in the enhancement of IL23A expression and that in addition to the expression of the protein, either posttranslational modifications $(48,49)$ or formation of an enhanceosome with other factors may be necessary for full development of transcriptional activity (50). Since sXBP1 also plays a central role in the control of the hexosamine biosynthetic pathway by regulating the expression of GFPT1 (51), the expression of this enzyme and the binding of sXBP1 to an X-box placed 147 bp upstream of the transcription initiation nucleotide were addressed. Resting DCs showed a high expression of GFPT1 mRNA, which was significantly enhanced when DCs were stimulated with either zymosan or LPS in the presence of 2-DG (Figure 8E). Notably, binding of sXBP1 to the X-box of GFPT1 showed a parallel enhancement under these conditions (Figure 8F). These results confirm the presence of detectable amounts of sXBP1 protein in resting DCs in the absence of definite XBP1 mRNA splicing and suggest that in addition to the expression of protein, posttranslational modifications or interaction with other factors may be necessary for its transcriptional activity. 
A

P-T71-ATF2 binding

to the IL23A promoter

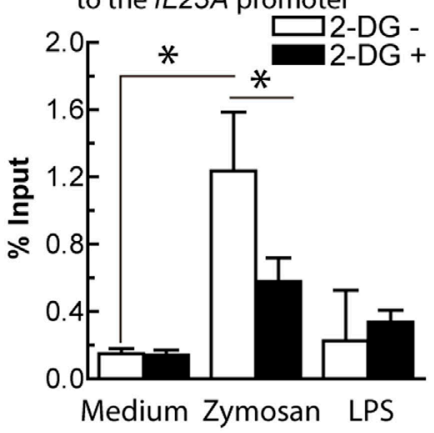

C

sXBP1 binding to the IL23A promoter Proximal Medial Distal

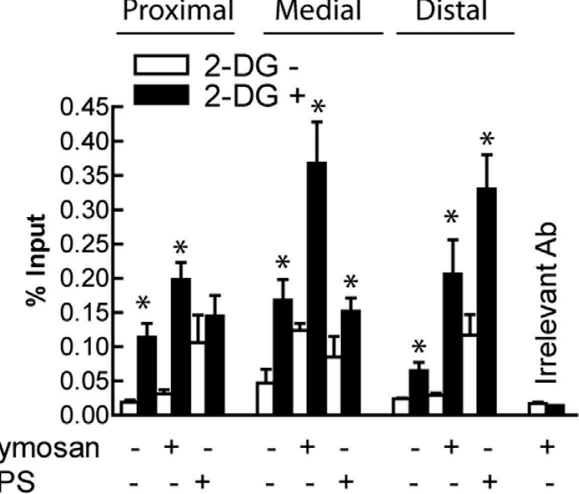

$\mathbf{E}$

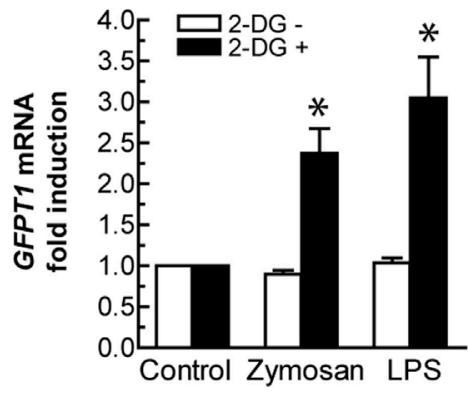

B

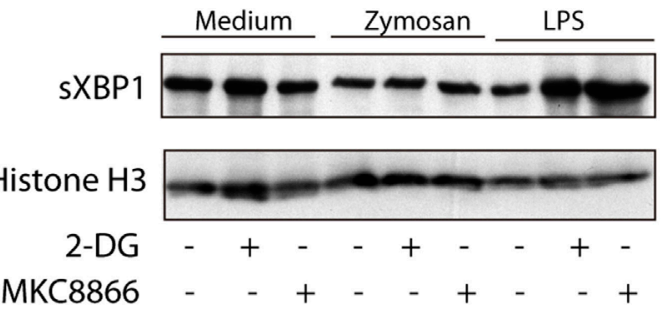

D C/EBP $\beta$ binding to the IL23A promoter Proximal Medial Distal

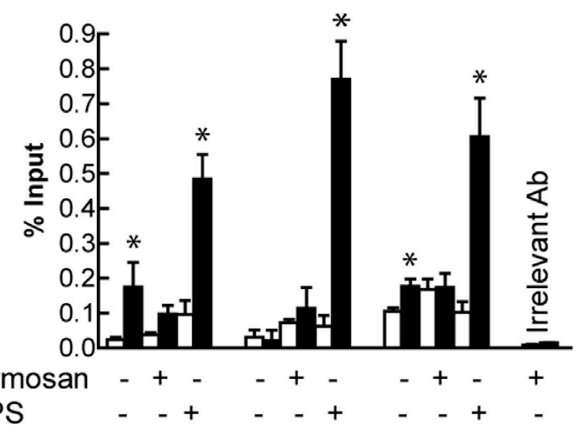

$\mathbf{F}$ sXBP1 binding to the GFPT1 promoter

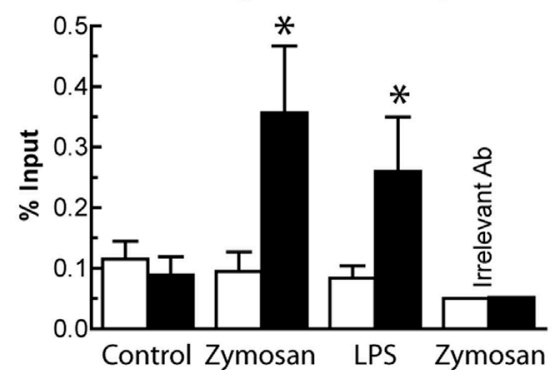

FIGURE 8 | Transcription factors involved in IL23A and glutamine-fructose-6-phosphate transaminase 1 (GFPT1) mRNA expression. (A) Effect of 2-deoxy-D-glucose (2-DG) on the binding of P-T71-ATF2 to the ATF2 consensus binding sequence in the IL23A promoter. (B) Expression of spliced X-box binding protein 1 (sXBP1) protein in nuclear fractions of dendritic cells (DCs) stimulated with zymosan and lipopolysaccharide (LPS) in the presence and absence of 2-DG and MKC8866. (C) Effect of 2-DG on the binding of sXBP1 to the X-boxes of the IL23A promoter after $1 \mathrm{~h}$ of stimulation with zymosan and LPS. (D) Binding of CAAT/enhancerbinding protein $\beta$ (C/EBP $\beta$ ) to C/EBP sites in the IL23A promoter. (E) Effect of 2-DG on the mRNA expression of GFPT1 mRNA in DCs stimulated for $4 \mathrm{~h}$ with zymosan and LPS. (F) Binding of sXBP1 to the X-box of the GFPT1 promoter $1 \mathrm{~h}$ after addition of the stimuli. Results show mean \pm SEM of three to five experiments $\left({ }^{*} p<0.05\right)$.

\section{2-DG Enhances C/EBP $\beta$ Binding Activity}

IL23A trans-activation by LPS has been associated with a set of factors including NF- $\mathrm{\kappa B}$, сAMP response element-binding protein (CREB), and C/EBP $\beta$. Consistent with this notion and the finding that inhibition of the IRE1 $\alpha$ and PERK routes showed stimulus-dependent effects, the binding of C/EBP $\beta$ to three sites in the IL23A promoter, two of which are close to two X-boxes and to a $\mathrm{\kappa B}$-site (21), was addressed. Unlike zymosan, 2-DG increased robustly the binding of C/EBP $\beta$ to the three sites (Figure 8D), thus suggesting the association of this factor with the enhancing effect of 2-DG on the expression of IL23A induced by LPS.

\section{Effect of the Deletion of Ern1 on II23a Expression}

Since the biochemical and pharmacological experiments suggested that the effect of the UPR on IL23A expression could be explained by a stimulus-dependent recruitment of the IRE1 $\alpha$ and the PERK routes, experiments were carried out in mice with hematopoietic system-specific deletion of Ernl, i.e., the gene 
encoding Ire1 $\alpha\left(E r n 1^{\mathrm{f} / \mathrm{f}}\right.$ Vav1-Cre mice $)$. As shown in Figure 9A, the sole addition of 2-DG induced Xbpl splicing in BMDCs from $E r n 1^{\mathrm{f} / \mathrm{f}}$ mice, which is a salient difference as compared to human DCs, in which both 2-DG and PAMPs are required for $X B P 1$ splicing. Ern1/f/fVav1-Cre mice did not show Xbp1 splicing, whereas Ddit3 mRNA expression was not significantly affected (Figure 9B). Notably, a substantial reduction in Il23a expression was observed in the Ern1 $1^{\mathrm{f} / \mathrm{f}}$ Vav1-Cre mice upon treatment with both LPS and zymosan in the presence of 2-DG, as compared to the $E r n 1^{\mathrm{f} / \mathrm{f}}$ mice (Figure 9C). Consistent with the results observed in DCs, pharmacological blockade of the PERK route with GSK2606414 inhibited Il23a mRNA expression in WT mice stimulated with LPS (Figure 9D). These results suggest the involvement of the Ire $1 \alpha$ route in response to both zymosan and LPS and of the PERK route in the case of LPS.

\section{DISCUSSION}

This study shows an increase of the extent of glycolysis along a wide array of concentrations of PAMPs and a rather stable tendency of the OCR in human DCs. The expression of HIF1 $\alpha$ protein shows a robust increase after $\sim 4 \mathrm{~h}$, which lags behind the glycolytic changes and suggests its involvement in the maintenance of the metabolic rewiring. These results are consistent with the occurrence of an early translocation of hexokinase II to the outer mitochondrial membrane, where it takes advantage of a privileged access to mitochondrial ATP. Given the central role of hexokinase and the widespread use of its inhibitor 2-DG, we addressed the effect of glucose starvation and 2-DG on cytokine expression. Whereas glucose starvation reduced the production of lactate after DCs stimulation to levels similar to those observed in resting DCs, 2-DG produced a less intense reduction. Unexpectedly, the expression of some cytokines showed marked differences, being the effect on IL23A mRNA most outstanding and seemingly dependent on the IRE $1 \alpha / \mathrm{XBP} 1$ arm of the UPR. The different effect of 2-DG on the induction of IL10 in response to zymosan and LPS agrees with the distinct trans-activating mechanisms elicited by these stimuli (38). At first glance, the effect of 2-DG could be associated with the reduction of lactate production, in keeping with the well-known function

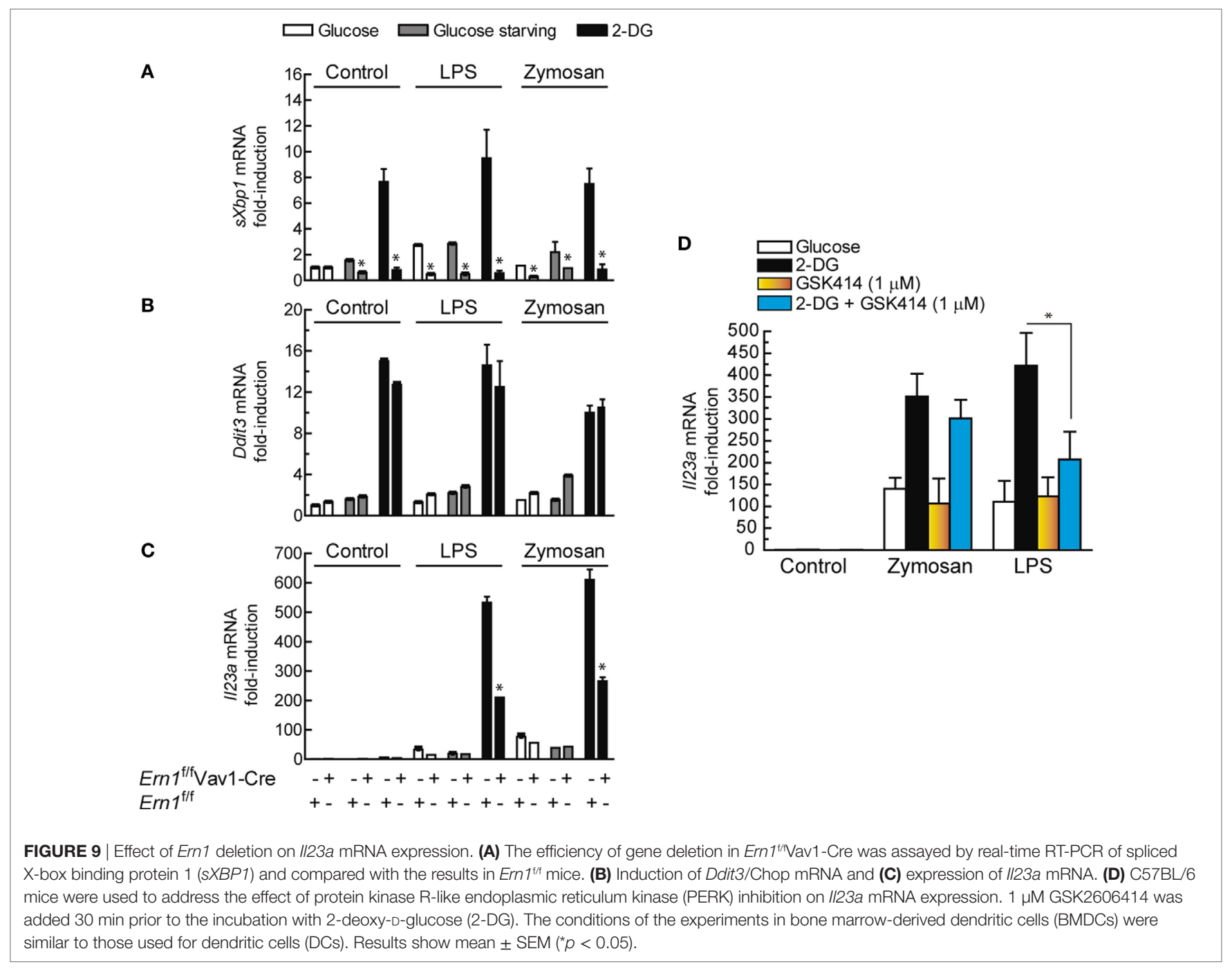


of lactate as a promoter of the differentiation of macrophages into the type M2 (3), and the observation that exogenous lactate at concentrations higher than those detected in the extracellular medium increased IL10 mRNA. However, a correlation of lactate production with IL10 mRNA expression could not be established since glucose deprivation was more efficient than 2-DG to reduce lactate production, while it did not affect IL10 mRNA expression. Although an unambiguous explanation of these findings cannot be given, an effect of lactate via GPR81 is plausible, since we have observed $\mathrm{Ca}^{2+}$ transients by perfusing DCs with $15 \mathrm{mM}$ lactate (data not shown). In addition, high concentrations of lactate have been found to induce GPR81-independent inhibition of pro-inflammatory responses and LPS-induced glycolysis in bone marrow macrophages (52). A different effect of glucose deprivation and 2-DG on cytokine production had been reported in human CD4 and CD8 T cells, although no mechanistic explanation was provided (53). A recent study has underscored the role of L-glutamine in the hexosamine biosynthesis pathway by enhancing the sXBP1- and $\alpha$-ketoglutarate-dependent expression of GFPT1 via mTORC2 activation, in an attempt to restore metabolic homeostasis. However, this was only observed after very long starvation or when both L-glutamine and glucose were exhausted (43). Since the immune response entails the coordination of gene expression and protein output to avoid the risk of building-up unfolded proteins, and 2-DG has been associated with the induction of the UPR via competition with $\mathrm{N}$-glycosylation reactions (24), the involvement of the transcription factors involved in the UPR was taken into account. The role of CHOP was proposed in a study carried out using a combination of LPS and tunicamycin (16), and the involvement of sXBP1 was suggested by showing that inhibition of ataxia telangiectasia mutated kinase by $\mu \mathrm{M}$ concentrations of the compound KU55933 increased the abundance of $s X B P 1$ mRNA and IL23A transcription (17). However, the experimental setting of those studies did not fit well with the actual occurrence of UPR and current views stand out the cooperation of NF- $\kappa \mathrm{B}$ proteins with ATF2, CREB, and C/EBP $\beta$ as the central mechanism involved in IL23A trans-activation by PAMPs (20, 21, 50, 54).

The induction of the UPR by 2-DG and tunicamycin has mechanistic commonalities since both drugs impinge on protein glycosylation. However, thapsigargin, which acts via SERCA inhibition, showed similar effects. These results indicate that the UPR rather than inhibition of $\mathrm{N}$-glycosylation on its one is involved in IL23A trans-activation. Experiments supported the activation of XBP1 by combination of 2-DG and PAMPs and its involvement in the regulation of IL23A in the zymosan system. As to the PERK/eIF2 $\alpha / \mathrm{ATF} 4 / \mathrm{CHOP}$ route, the data indicate a role of PERK in the LPS model, in agreement with the known link between translational repression and transcription of inflammatory genes (45). eIF $2 \alpha$ phosphorylation has been associated with the enhancement of NF- $\kappa \mathrm{B}$ activity via decreased levels of $\mathrm{I} \kappa \mathrm{B} \alpha$ protein, given the short life of this protein (55). A PERK/JAK1/ STAT3 route has been reported as a novel mechanism that contributes to ER stress-induced inflammation. Detection of ER stress by the ER-lumenal sensor domain dimerizes PERK and brings the interacting JAKs into proximity to allow trans-autophosphorylation, phosphorylation of the cytoplasmic domain of PERK at
Y585 and Y619 with the ensuing activation of its kinase activity, and S52-eIF2 $\alpha$ and Y705-STAT3 phosphorylation (56). Notably, P-Y705-STAT3 can be detected in the DCs system at early times as a result of the residual effect of the cytokines GM-CSF and IL-4 used to induce DCs differentiation (57), and later on as a result of the TRIF/TRAM branch of the LPS/TLR4 system or through the induction of secondary mediators (38). The interplay between the PERK and IRE1 $\alpha$ routes through STAT3 (Figure 10) is supported by recent data showing that STAT3 plays a critical role in the activation of a non-canonical UPR cascade involving Ire $1 \alpha$ and Xbp 1 under combined cytokine stimulation (58). Our finding of a stable phosphorylation of eIF2 $\alpha$ (Figure 7A) agrees with a recent report showing similar results in M2-polarized macrophages stimulated with LPS, thus suggesting that some stimuli activate the UPR in the absence of a stimulatory effect on eIF2 $\alpha$ phosphorylation (44).

Further mechanistic insight was provided by experiments in the Ire $1 \alpha$-deficient mice, by showing that a significant part of the effect could be associated unambiguously with the IRE1 $\alpha$ route. In the case of zymosan it also involved sXBP1, although other mechanisms cannot be ruled out, e.g., the formation of a complex of I $\mathrm{B}$ kinase (IKK) with IRE1 $\alpha$ through the adaptor protein TRAF2, given that NF- $\kappa B$ activation is impaired under ER stress conditions in IRE1 $\alpha$ knockdown cells and Ern $1^{-1-}$ mouse embryonic fibroblasts (59). A recent study has enlarged the reciprocity of connections between IKK and the IRE $1 \alpha$ route by showing that IKK $\beta$ directly phosphorylates sXBP1 at T48 and S148 residues (49). Surprisingly, another study has unveiled a role of XBP1 as a moonlighting protein, since its antilipogenic activity is mediated through a protein-protein interaction that ultimately reduces cytoplasm-to-membrane translocation of PKCE (60).

Our suggestion that the PERK branch is involved in response to LPS mainly stems on pharmacological studies. Given that GSK2606414 has been recently reported to be an active inhibitor of RIPK1 in TNF $\alpha$-RIPK1 kinase-dependent models, we extended the experiments using AMP PERK 44 (30), which does not exhibit that effect. Results are consistent with PERK activity inhibition and do not suggest RIPK1 involvement in IL23A induction. An open question is the association of $\mathrm{C} / \mathrm{EBP} \beta$ with the UPR. C/EBP $\beta$ has been found to induce the transcriptional activation of $X B P 1$ $(61,62)$ and, conversely, C/EBP $\beta$ is induced by XBP1 via an X-box present in human cells that is absent in rats and mice (63), as well as through the PERK route (64). In addition, C/EBP $\beta$ is fully active in unstimulated macrophages and poised to be recruited into enhanceosomes to team up with other factors to stimulate transcription, given its well-known function as a pioneer factor that promotes the opening of silent chromatin $(49,65,66)$. The present results are of clinical relevance because DCs in tumor milieus show an activation of XBP1 that blunts the immune response and favors tumor cell progression (13). This agrees with a previous report where the poor prognosis of triple-negative breast cancers correlated with the assembly of a transcriptional complex of XBP1 and HIF1 $\alpha$ (67). The present study extends the clinical relevance of those reports by showing that the stimulation by PAMPs under conditions of ER stress imprints the cytokine response into a pattern favorable to tumor progression. In fact, the production of IL-23 by tumor-associated myeloid cells in tissues 


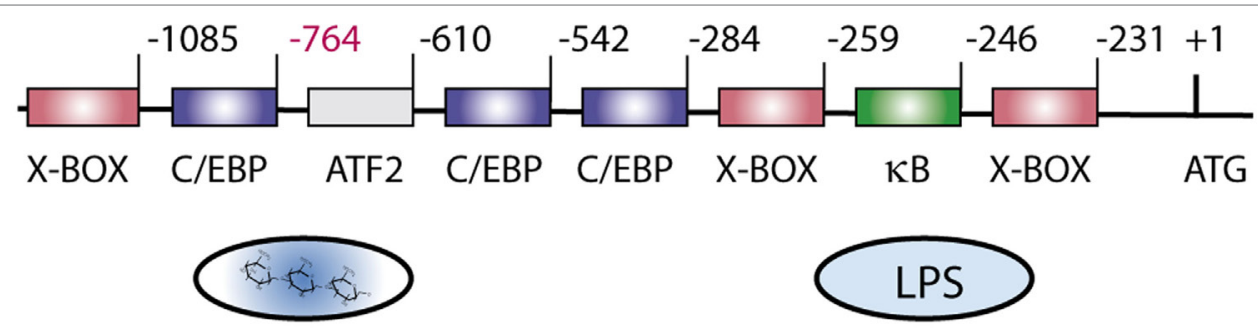

$\beta(1,3)$-glucans $\quad \alpha$-mannans

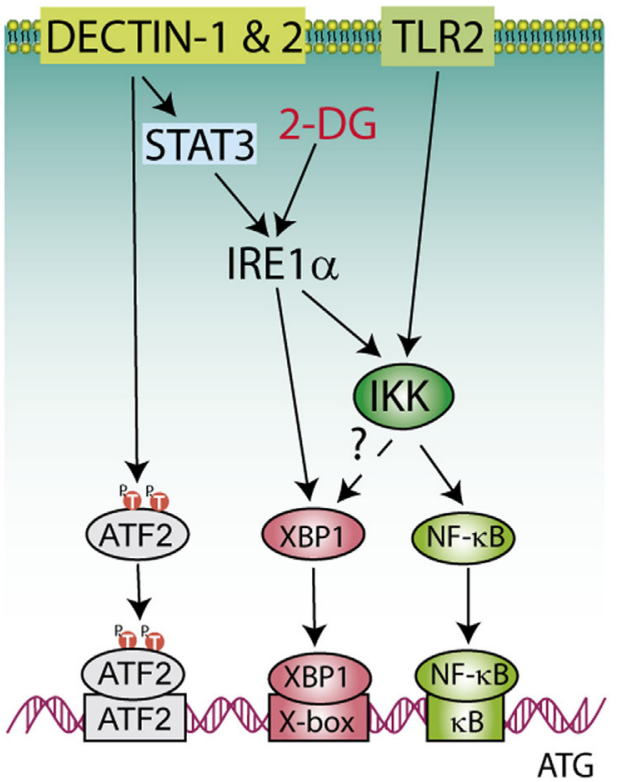

IL23A promoter
ATG

$+1$

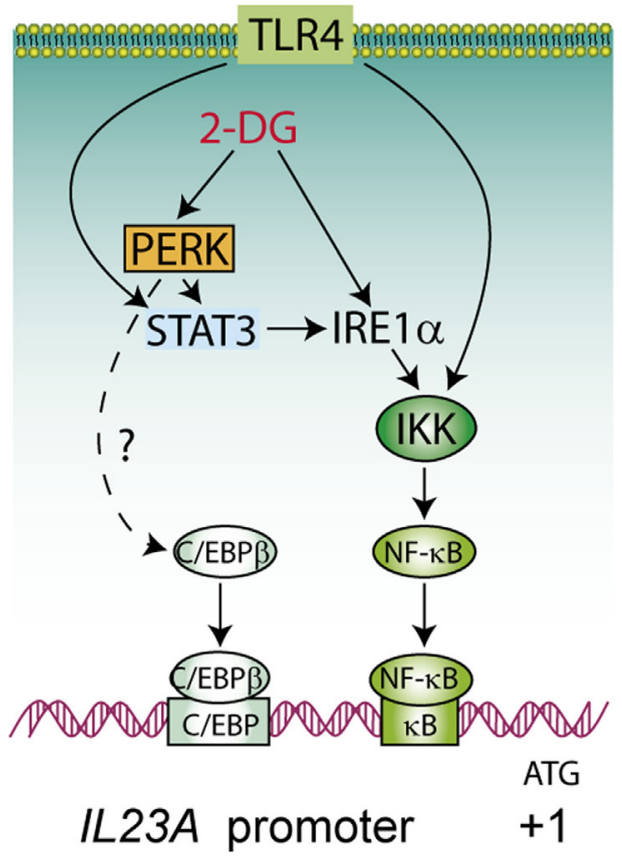

ATG

IL23A promoter

FIGURE 10 | Explanatory diagram of the routes involved in the transcriptional regulation of the p19 chain of IL-23 during the unfolded protein response (UPR). The structure of the IL23A proximal promoter is shown on top of the diagrams underscoring the regulatory elements where activating transcription factor 2 (ATF2), $\mathrm{X}$-box

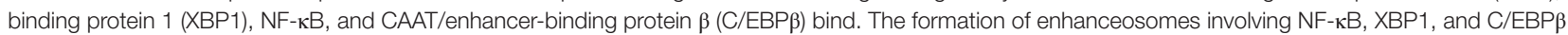
seems most likely and the combinatory usage of elements may depend on the nature of the stimulus. The inositol-requiring protein $1 \alpha$ (IRE $1 \alpha$ ) route is involved in all cases and impinges at least on NF-kB activation and on XBP1 activity in the case of zymosan. STAT3 is activated by fungal patterns via secondary mediators not yet identified, whereas in the case of lipopolysaccharide (LPS) the activation depends on IFN $\beta$ and IRF3 downstream of the TRIF/TRAM adaptors of the LPS/TLR4 system. C/EBP $\beta$ and the PERK route seem more relevant in the case of LPS. Discontinuous lines indicate routes non-addressed in the current experiments but which are supported on other studies $(38,49,59-64)$.

accessible to microbial products is a major driver of tumor growth, for instance in colon cancer (15). Noteworthy, GM-CSF exerts a robust effect on atherogenesis via the production of IL-23 (68) and a recent report has shown that inhibition of the ribonuclease activity of Ire $1 \alpha$ by $4 \mu 8 \mathrm{C}$ counteracts atherosclerosis progression (69). Therefore, a major contribution of Ire $1 \alpha$ to atherogenesis may rely on its ability to enhance IL-23 production. Most recent reports have confirmed in clinical studies the beneficial effect of blocking IL-23 activity in psoriasis (70) and Crohn's disease (71). Most remarkable, increasing target selectivity with risankizumab, an antibody reactive to the 19 chain, induced clinical responses superior to those associated with ustekinumab, an antibody reactive to the p40 chain, which is shared by both IL-12 p70 and IL-23 (70). In summary, these data show a net enhancement of glycolysis in DCs stimulated with PAMPs. The use of the hexokinase inhibitor 2-DG disclosed robust changes of IL23A transcription that were not reproduced by glucose starvation and pointed to the activation of the UPR via interference with mannose metabolism and N-glycosylation reactions. These data indicate that the current mechanism of transcriptional regulation of IL23A induced by PAMPs via the recruitment of NF- $\kappa \mathrm{B}, \mathrm{ATF} 2$, and $\mathrm{C} / \mathrm{EBP} \beta$ can be reinforced by the recruitment of the IRE1 $\alpha$ and PERK arms of the UPR. An explanatory diagram of the routes involved is shown in Figure 10.

\section{ETHICS STATEMENT}

The study was approved by the Bioethical Committee of the Spanish Council of Research (CSIC) and the written informed consent of all healthy donors was obtained at Centro de Hemoterapia y Hemodonación de Castilla y León Biobank. The participants received written consent according to the regulations 
of the Biobank and the researchers received the samples in an anonymous way. The process is documented by the Biobank authority according to the specific Spanish regulations. The animal experiments were carried out with permission of the local authority and conform to institutional standards. The ethics committee approved this procedure before starting the study.

\section{AUTHOR CONTRIBUTIONS}

SM, JF, SA, ET-C, CH, OM, and AA conducted experiments and drafted the work. TI, JC-R, NF, and MC designed the experiments and interpreted the data. All authors reviewed and approved the manuscript. JC-R and MC wrote the article.

\section{REFERENCES}

1. Okabe Y, Medzhitov R. Tissue biology perspective on macrophages. Nat Immunol (2016) 17:9-17. doi:10.1038/ni.3320

2. Lu H, Forbes RA, Verma A. Hypoxia-inducible factor 1 activation by aerobic glycolysis implicates the Warburg effect in carcinogenesis. J Biol Chem (2002) 277:23111-5. doi:10.1074/jbc.M202487200

3. Colegio OR, Chu NQ, Szabo AL, Chu T, Rhebergen AM, Jairam V, et al. Functional polarization of tumour-associated macrophages by tumourderived lactic acid. Nature (2014) 513:559-63. doi:10.1038/nature13490

4. Tannahill GM, Curtis AM, Adamik J, Palsson-McDermott EM, McGettrick AF, Goel G, et al. Succinate is an inflammatory signal that induces IL- $1 \beta$ through HIF-1 $\alpha$. Nature (2013) 496:238-42. doi:10.1038/nature11986

5. De Ponti C, Carini R, Alchera E, Nitti MP, Locati M, Albano E, et al. Adenosine A2a receptor-mediated, normoxic induction of HIF-1 through PKC and PI-3K-dependent pathways in macrophages. J Leukoc Biol (2007) 82:392-402. doi:10.1189/jlb.0107060

6. Mekhail K, Gunaratnam L, Bonicalzi ME, Lee S. HIF activation by pHdependent nucleolar sequestration of VHL. Nat Cell Biol (2004) 6:642-7. doi:10.1038/ncb1144

7. Nadtochiy SM, Schafer X, Fu D, Nehrke K, Munger J, Brookes PS. Acidic pH is a metabolic switch for 2-hydroxyglutarate generation and signaling. J Biol Chem (2016) 291:20188-97. doi:10.1074/jbc.M116.738799

8. Liu C, Wu J, Zhu J, Kuei C, Yu J, Shelton J, et al. Lactate inhibits lipolysis in fat cells through activation of an orphan G-protein-coupled receptor, GPR81. J Biol Chem (2009) 284:2811-22. doi:10.1074/jbc.M806409200

9. Rubic T, Lametschwandtner G, Jost S, Hinteregger S, Kund J, Carballido-Perrig N, et al. Triggering the succinate receptor GPR91 on dendritic cells enhances immunity. Nat Immunol (2008) 9:1261-9. doi:10.1038/ni.1657

10. Yoshida H, Matsui T, Yamamoto A, Okada T, Mori K. XBP1 mRNA is induced by ATF6 and spliced by IRE1 in response to ER stress to produce a highly active transcription factor. Cell (2001) 107:881-91. doi:10.1016/ S0092-8674(01)00611-0

11. Iwakoshi NN, Pypaert M, Glimcher LH. The transcription factor XBP-1 is essential for the development and survival of dendritic cells. J Exp Med (2007) 204:2267-75. doi:10.1084/jem.20070525

12. Martinon F, Chen X, Lee AH, Glimcher LH. TLR activation of the transcription factor XBP1 regulates innate immune responses in macrophages. Nat Immunol (2010) 11:411-8. doi:10.1038/ni.1857

13. Cubillos-Ruiz JR, Silberman PC, Rutkowski MR, Chopra S, Perales-Puchalt A, Song $\mathrm{M}$, et al. ER stress sensor XBP1 controls anti-tumor immunity by disrupting dendritic cell homeostasis. Cell (2015) 161:1527-38. doi:10.1016/ j.cell.2015.05.025

14. Delay ML, Turner MJ, Klenk EI, Smith JA, Sowders DP, Colbert RA. HLAB27 misfolding and the unfolded protein response augment interleukin-23 production and are associated with Th17 activation in transgenic rats. Arthritis Rheum (2009) 60:2633-43. doi:10.1002/art.24763

15. Grivennikov SI, Wang K, Mucida D, Stewart CA, Schnabl B, Jauch D, et al. Adenoma-linked barrier defects and microbial products drive IL-23/IL-17mediated tumour growth. Nature (2012) 491:254-8. doi:10.1038/nature11465

\section{ACKNOWLEDGMENTS}

Dr. Eduardo Rial is thanked for help with bionergetic experiments. Dr. John Patterson from MannKind Corporation is thanked for the gift of MKC8866.

\section{FUNDING}

$\mathrm{CH}$ is the recipient of a grant from Sociedad Española de Hematología y Hemoterapia. This work was supported by grants from Plan Nacional de Salud y Farmacia (grants SAF201344521-R) and Fundación Domingo Martínez.

16. Goodall JC, Wu C, Zhang Y, McNeill L, Ellis L, Saudek V, et al. Endoplasmic reticulum stress-induced transcription factor, CHOP, is crucial for dendritic cell IL-23 expression. Proc Natl Acad Sci U S A (2010) 107:17698-703. doi:10.1073/pnas.1011736107

17. Wang Q, Franks HA, Lax SJ, El Refaee M, Malecka A, Shah S, et al. The ataxia telangiectasia mutated kinase pathway regulates IL-23 expression by human dendritic cells. J Immunol (2013) 190:3246-55. doi:10.4049/jimmunol. 1201484

18. Woo CW, Cui D, Arellano J, Dorweiler B, Harding H, Fitzgerald KA, et al. Adaptive suppression of the ATF4-CHOP branch of the unfolded protein response by toll-like receptor signalling. Nat Cell Biol (2009) 11:1473-80. doi:10.1038/ncb1996

19. Woo CW, Kutzler L, Kimball SR, Tabas I. Toll-like receptor activation suppresses ER stress factor $\mathrm{CHOP}$ and translation inhibition through activation of eIF2B. Nat Cell Biol (2012) 14:192-200. doi:10.1038/ncb2408

20. Brain O, Owens BM, Pichulik T, Allan P, Khatamzas E, Leslie A, et al. The intracellular sensor NOD2 induces microRNA-29 expression in human dendritic cells to limit IL-23 release. Immunity (2013) 39:521-36. doi:10.1016/j. immuni.2013.08.035

21. Rodríguez M, Domingo E, Alonso S, Frade JG, Eiros J, Sanchez Crespo M, et al. The unfolded protein response and the phosphorylations of activating transcription factor 2 in the trans-activation of IL23A promoter produced by $\beta$-glucans. J Biol Chem (2014) 289:22942-57. doi:10.1074/jbc.M113. 522656

22. Grossbard L, Schimke RT. Multiple hexokinases of rat tissues. Purification and comparison of soluble forms. J Biol Chem (1966) 241:3546-60.

23. Wang A, Huen SC, Luan HH, Yu S, Zhang C, Gallezot JD, et al. Opposing effects of fasting metabolism on tissue tolerance in bacterial and viral inflammation. Cell (2016) 166:1512-25. doi:10.1016/j.cell.2016.07.026

24. Kurtoglu M, Maher JC, Lampidis TJ. Differential toxic mechanisms of 2-deoxyD-glucose versus 2-fluorodeoxy-D-glucose in hypoxic and normoxic tumor cells. Antioxid Redox Signal (2007) 9:1383-90. doi:10.1089/ars.2007.1714

25. Andresen L, Skovbakke SL, Persson G, Hagemann-Jensen M, Hansen KA, Jensen $\mathrm{H}$, et al. 2-Deoxy D-glucose prevents cell surface expression of NKG2D ligands through inhibition of N-linked glycosylation. J Immunol (2012) 188:1847-55. doi:10.4049/jimmunol.1004085

26. Yu SM, Kim SJ. Endoplasmic reticulum stress (ER-stress) by 2-deoxy-D-glucose (2DG) reduces cyclooxygenase-2 (COX-2) expression and $\mathrm{N}$-glycosylation and induces a loss of COX-2 activity via a Src kinase-dependent pathway in rabbit articular chondrocytes. Exp Mol Med (2010) 42:777-86. doi:10.3858/ emm.2010.42.11.079

27. Otto JC, DeWitt DL, Smith WL. N-glycosylation of prostaglandin endoperoroxide synthases- 1 and -2 and their orientations in the endoplasmic reticulum. J Biol Chem (1993) 268:18234-42.

28. Mimura N, Fulciniti M, Gorgun G, Tai YT, Cirstea D, Santo L, et al. Blockade of XBP1 splicing by inhibition of IRE1 $\alpha$ is a promising therapeutic option in multiple myeloma. Blood (2012) 119:5772-81. doi:10.1182/ blood-2011-07-366633

29. Smith AL, Andrews KL, Beckmann H, Bellon SF, Beltran PJ, Booker S, et al. Discovery of $1 \mathrm{H}$-pyrazol-3(2H)-ones as potent and selective inhibitors of 
protein kinase R-like endoplasmic reticulum kinase (PERK). J Med Chem (2015) 58:1426-41. doi:10.1021/jm5017494

30. Rojas-Rivera D, Delvaeye T, Roelandt R, Nerinckx W, Augustyns K, Vandenabeele P, et al. When PERK inhibitors turn out to be new potent RIPK1 inhibitors: critical issues on the specificity and use of GSK2606414 and GSK2656157. Cell Death Differ (2017). doi:10.1038/cdd.2017.58

31. Rodríguez M, Márquez S, Montero O, Alonso S, Frade JG, Sánchez Crespo M, et al. Pharmacological inhibition of eicosanoids and platelet-activating factor signaling impairs zymosan-induced release of IL- 23 by dendritic cells. Biochem Pharmacol (2016) 102:78-96. doi:10.1016/j.bcp.2015. 12.001

32. Palsson-McDermott EM, Curtis AM, Goel G, Lauterbach MA, Sheedy FJ, Gleeson LE, et al. Pyruvate kinase M2 regulates Hif- $1 \alpha$ activity and IL- $1 \beta$ induction and is a critical determinant of the Warburg effect in LPSactivated macrophages. Cell Metab (2015) 21:65-80. doi:10.1016/j.cmet.2014. 12.005

33. Luo W, Hu H, Chang R, Zhong J, Knabel M, O’Meally R, et al. Pyruvate kinase M2 is a PHD3-stimulated coactivator for hypoxia-inducible factor 1. Cell (2011) 145:732-44. doi:10.1016/j.cell.2011.03.054

34. Gao X, Wang H, Yang JJ, Liu X, Liu ZR. Pyruvate kinase M2 regulates gene transcription by acting as a protein kinase. Mol Cell (2012) 45:598-609. doi:10.1038/ni.2833

35. Yang W, Xia Y, Hawke D, Li X, Liang J, Xing D, et al. PKM2 phosphorylates histone $\mathrm{H} 3$ and promotes gene transcription and tumorigenesis. Cell (2012) 150:685-96. doi:10.1016/j.cell.2012.07.018

36. Dang EV, Barbi J, Yang HY, Jinasena D, Yu H, Zheng Y, et al. Control of $\mathrm{T}_{\mathrm{H}} 17 / \mathrm{T}_{\text {reg }}$ balance by hypoxia-inducible factor 1 . Cell (2011) 146:772-84. doi:10.1016/j.cell.2011.07.033

37. Shehade H, Acolty V, Moser M, Oldenhove G. Cutting edge: hypoxiainducible factor 1 negatively regulates Th1 function. J Immunol (2015) 195: 1372-6. doi:10.4049/jimmunol.1402552

38. Rodríguez M, Marquez S, de la Rosa JV, Alonso S, Castrillo A, Sanchez Crespo M, et al. Fungal pattern receptors down-regulate the inflammatory response by a cross-inhibitory mechanism independent of IL-10 production. Immunology (2017) 150:184-98. doi:10.1111/imm.12678

39. Everts B, Amiel E, Huang SC, Smith AM, Chang CH, Lam WY, et al. TLRdriven early glycolytic reprogramming via the kinases TBK1-IKKe supports the anabolic demands of dendritic cell activation. Nat Immunol (2014) 15:323-32. doi:10.1038/ni.2833

40. Michl J, Ohlbaum DJ, Silverstein SC. 2-Deoxyglucose selectively inhibits Fc and complement receptor-mediated phagocytosis in mouse peritoneal macrophages. I. Description of the inhibitory effect. J Exp Med (1976) 144:1465-83. doi:10.1084/jem.144.6.1465

41. Michl J, Ohlbaum DJ, Silverstein SC. 2-Deoxyglucose selectively inhibits Fc and complement receptor-mediated phagocytosis in mouse peritoneal macrophages II. Dissociation of the inhibitory effects of 2-deoxyglucose on phagocytosis and ATP generation. JExp Med (1976) 144:1484-93. doi:10.1084/ jem.144.6.1465

42. Araujo L, Khim P, Mkhikian H, Mortales CL, Demetriou M. Glycolysis and glutaminolysis cooperatively control T cell function by limiting metabolite supply to N-glycosylation. Elife (2017) 6:e21330. doi:10.7554/eLife. 21330

43. Moloughney JG, Kim PK, Vega-Cotto NM, Wu CC, Zhang S, Adlam M, et al. mTORC2 responds to glutamine catabolite levels to modulate the hexosamine biosynthesis enzyme GFAT1. Mol Cell (2016) 63:811-26. doi:10.1016/j. molcel.2016.07.015

44. Shan B, Wang X, Wu Y, Xu C, Xia Z, Dai J, et al. The metabolic ER stress sensor IRE1 $\alpha$ suppresses alternative activation of macrophages and impairs energy expenditure in obesity. Nat Immunol (2017) 18:519-29. doi:10.1038/ ni.3709

45. Guthrie LN, Abiraman K, Plyler ES, Sprenkle NT, Gibson SA, McFarland BC, et al. Attenuation of PKR-like ER kinase (PERK) signaling selectively controls endoplasmic reticulum stress-induced inflammation without compromising immunological responses. J Biol Chem (2016) 291:15830-40. doi:10.1074/jbc. M116.738021

46. Hong $\mathrm{M}$, Luo S, Baumeister P, Huang J-M, Gogia RK, Li M, et al. Underglycosylation of ATF6 as a novel sensing mechanism for activation of the unfolded protein response. J Biol Chem (2004) 279:11354-63. doi:10.1074/ jbc.M309804200

47. Acosta-Alvear D, Zhou Y, Blais A, Tsikitis M, Lents NH, Arias C, et al. XBP1 controls diverse cell-type and condition-specific transcriptional regulatory networks. Mol Cell (2007) 27:53-66. doi:10.1016/j.molcel.2007.06.011

48. Lee J, Sun C, Zhou Y, Lee J, Gokalp D, Herrema H, et al. p38 MAPK-mediated regulation of Xbp1s is crucial for glucose homeostasis. Nat Med (2011) 17:1251-60. doi:10.1038/nm.2449

49. Liu J, Ibi D, Taniguchi K, Lee J, Herrema H, Akosman B, et al. Inflammation improves glucose homeostasis through IKK $\beta$-XBP1s interaction. Cell (2016) 167:1052-66. doi:10.1016/j.cell.2016.10.015

50. Kocieda VP, Adhikary S, Emig F, Yen JH, Toscano MG, Ganea D. Prostaglandin $\mathrm{E}_{2}$-induced IL-23p19 subunit is regulated by cAMP-responsive elementbinding protein and C/AATT enhancer-binding protein $\beta$ in bone marrowderived dendritic cells. J Biol Chem (2012) 287:36922-35. doi:10.1074/jbc. M112.402958

51. Wang ZV, Deng Y, Gao N, Pedrozo Z, Li DL, Morales CR, et al. Spliced X-box binding protein 1 couples the unfolded protein response to hexosamine biosynthetic pathway. Cell (2014) 156:1179-92. doi:10.1016/j.cell.2014. 01.014

52. Errea A, Cayet D, Marchetti P, Tang C, Kluza J, Offermanns S, et al. Lactate inhibits the pro-inflammatory response and metabolic reprogramming in murine macrophages in a GPR81-independent manner. PLoS One (2016) 11(11):e0163694. doi:10.1371/journal.pone.0163694

53. Renner K, Geiselhöringer AL, Fante M, Bruss C, Färber S, Schönhammer G, et al. Metabolic plasticity of human T cells: preserved cytokine production under glucose deprivation or mitochondrial restriction, but 2-deoxy-glucose affects effector functions. Eur J Immunol (2015) 45:2504-16. doi:10.1002/eji. 201545885

54. Al-Salleeh F, Petro TM. Promoter analysis reveals critical roles for SMAD-3 and ATF-2 in expression of IL-23 p19 in macrophages. J Immunol (2008) 181:4523-33. doi:10.4049/jimmunol.181.7.4523

55. Deng J, Lu PD, Zhang Y, Scheuner D, Kaufman RJ, Sonenberg N, et al. Translational repression mediates activation of NF- $\mathrm{\kappa B}$ by phosphorylated translation initiation factor 2. Mol Cell Biol (2004) 24:10161-8. doi:10.1128/ MCB.24.23.10161-10168.2004

56. Meares GP, Liu Y, Rajbhandari R, Qin H, Nozell SE, Mobley JA, et al. PERK-dependent activation of JAK1 and STAT3 contributes to endoplasmic reticulum stress-induced inflammation. Mol Cell Biol (2014) 34:3911-25. doi:10.1128/MCB.00980-14

57. Alvarez Y, Municio C, Alonso S, Sánchez Crespo M, Fernández N. The induction of IL-10 by zymosan in dendritic cells depends on CREB activation by the coactivators CREB-binding protein and TORC2 and autocrine $\mathrm{PGE}_{2}$. J Immunol (2009) 183:1471-9. doi:10.4049/jimmunol.0900312

58. Yan D, Wang HW, Bowman RL, Joyce JA. STAT3 and STAT6 signaling pathways synergize to promote cathepsin secretion from macrophages via IRE1 $\alpha$ activation. Cell Rep (2016) 16:2914-27. doi:10.1016/j.celrep.2016. 08.035

59. Hu P, Han Z, Couvillon AD, Kaufman RJ, Exton JH. Autocrine tumor necrosis factor alpha links endoplasmic reticulum stress to the membrane death receptor pathway through IRE1 $\alpha$-mediated NF-kB activation and downregulation of TRAF2 expression. Mol Cell Biol (2006) 26:3071-84. doi:10.1128/ MCB.26.8.3071-3084.2006

60. Herrema H, Zhou Y, Zhang D, Lee J, Salazar Hernandez MA, Shulman GI, et al. XBP1s is an anti-lipogenic protein. J Biol Chem (2016) 291:17394-404. doi:10.1074/jbc.M116.728949

61. Sha H, He Y, Chen H, Wang C, Zenno A, Shi H, et al. The IRE1 $\alpha$-XBP1 pathway of the unfolded protein response is required for adipogenesis. Cell Metab (2009) 9:556-64. doi:10.1016/j.cmet.2009.04.009

62. Guo L, Li X, Tang Q-Q. Transcriptional regulation of adipocyte differentiation: a central role for CCAAT/enhancer-binding protein (C/EBP) $\beta$. J Biol Chem (2015) 290:755-61. doi:10.1074/jbc.R114.619957

63. Chen C, Dudenhausen EE, Pan YX, Zhong C, Kilberg MS. Human CCAAT/ enhancer-binding protein $\beta$ gene expression is activated by endoplasmic reticulum stress through an unfolded protein response element downstream of the protein coding sequence. J Biol Chem (2004) 279:27948-56. doi:10.1074/jbc. M313920200 
64. Hayakawa K, Nakajima S, Hiramatsu N, Okamura M, Huang T, Saito Y, et al. ER stress depresses NF- $\kappa B$ activation in mesangial cells through preferential induction of C/EBP $\beta$. J Am Soc Nephrol (2010) 21:73-81. doi:10.1681/ASN. 2009040432

65. Plevy SE, Gemberling JH, Hsu S, Dorner AJ, Smale ST. Multiple control elements mediate activation of the murine and human interleukin 12 p40 promoters: evidence of functional synergy between C/EBP and Rel proteins. Mol Cell Biol (1997) 17:4572-88. doi:10.1128/MCB.17.8.4572

66. Bradley MN, Zhou L, Smale ST. C/EBP $\beta$ regulation in lipopolysaccharide-stimulated macrophages. Mol Cell Biol (2003) 23:4841-58. doi:10.1128/ MCB.23.14.4841-4858.2003

67. Chen X, Iliopoulos D, Zhang Q, Tang Q, Greenblatt M, Hatziapostolou M, et al. XBP1 promotes triple-negative breast cancer by controlling the HIF1 $\alpha$ pathway. Nature (2014) 508:103-7. doi:10.1038/nature13119

68. Subramanian M, Thorp E, Tabas I. Identification of a non-growth factor role for GM-CSF in advanced atherosclerosis: promotion of macrophage apoptosis and plaque necrosis through IL-23 signaling. Circ Res (2015) 116:e13-24. doi:10.1161/CIRCRESAHA.116.304794

69. Tufanli O, Telkoparan Akillilar P, Acosta-Alvear D, Kocaturk B, Onat UI, Hamid SM, et al. Targeting IRE1 with small molecules counteracts progression of atherosclerosis. Proc Natl Acad Sci U S A (2017) 114:E1395-404. doi:10.1073/pnas.1621188114
70. Papp KA, Blauvelt A, Bukhalo M, Gooderham M, Krueger J, Lacour JP, et al. Risankizumab versus ustekinumab for moderate-to-severe plaque psoriasis. $N$ Engl J Med (2017) 376:1551-60. doi:10.1056/NEJMoa1607017

71. Feagan BG, Sandborn WJ, D’Haens G, Panés J, Kaser A, Ferrante M, et al. Induction therapy with the selective interleukin-23 inhibitor risankizumab in patients with moderate-to-severe Crohn's disease: a randomised, double-blind, placebo-controlled phase 2 study. Lancet (2017) 389:1699-709. doi:10.1016/ S0140-6736(17)30570-6

Conflict of Interest Statement: JC-R is a co-founder and scientific advisor for Quentis Therapeucis Inc. The role of this author was to design experiments, analyze data, provide reagents and materials, and write the manuscript. All other authors declare no competing interests.

Copyright (C) 2017 Márquez, Fernández, Terán-Cabanillas, Herrero, Alonso, Azogil, Montero, Iwawaki, Cubillos-Ruiz, Fernández and Crespo. This is an open-access article distributed under the terms of the Creative Commons Attribution License (CC $B Y)$. The use, distribution or reproduction in other forums is permitted, provided the original author(s) or licensor are credited and that the original publication in this journal is cited, in accordance with accepted academic practice. No use, distribution or reproduction is permitted which does not comply with these terms. 